\title{
A DYNAMIC THEORY OF RESOURCE WARS*
}

\author{
DARON ACEMOGLU \\ MIKHAIL GOLOSOV \\ ALEH TSYVINSKI \\ PIERRE YARED
}

We develop a dynamic theory of resource wars and study the conditions under which such wars can be prevented. Our focus is on the interaction between the scarcity of resources and the incentives for war in the presence of limited commitment. We show that a key parameter determining the incentives for war is the elasticity of demand. Our first result identifies a novel externality that can precipitate war: price-taking firms fail to internalize the impact of their extraction on military action. In the case of inelastic resource demand, war incentives increase over time and war may become inevitable. Our second result shows that in some situations, regulation of prices and quantities by the resource-rich country can prevent war, and when this is the case, there will also be slower resource extraction than the Hotelling benchmark (with inelastic demand). Our third result is that because of limited commitment and its implications for armament incentives, regulation of prices and quantities might actually precipitate war even in some circumstances where wars would not have arisen under competitive markets. JEL Codes: F10, F51, H56, Q32.

\section{INTRODUCTION}

Control over natural resources has been one of the key determinants of wars. ${ }^{1}$ An early study of causes of modern wars during the 1878 to 1918 period by Bakeless (1921) argued that 14

${ }^{*}$ We thank V. V. Chari, Elhanan Helpman, Larry Jones, Antonio Merlo, Gerard Padró i Miquel, Kristopher Ramsay, Stergios Skaperdas, Enrico Spolaore, three anonymous referees, and seminar participants at Berkeley, the Canadian Institute for Advanced Research, Kellogg MEDS, New York University, the Princeton-Yale Conference on War and Trade, NBER, and the Society for the Advancement of Economic Theory Conference for comments. We thank Nick Werquin for excellent research assistance Acemoglu gratefully acknowledges financial support from the NSF, the ARO, and the Canadian Institute for Advanced Research. Golosov and Tsyvinski gratefully acknowledge financial support from the NSF. Golosov, Tsyvinski, and Yared thank EIEF for its hospitality.

1. In his classic, A Study of War, Wright (1942) devotes a chapter to the relationship between war and resources. Another classic reference, Statistics of Deadly Quarrels by Richardson (1960), extensively discusses economic causes of war, including the control of "sources of essential commodities." A large literature pioneered by Homer-Dixon $(1991,1999)$ argues that scarcity of various environmental resources is a major cause of conflict and resource wars (see Toset, Gleditsch, and Hegre 2000, for empirical evidence). More recently, Findlay and O'Rourke (2007) document the historical relationship between international trade and military conflict.

(C) The Author(s) 2012. Published by Oxford University Press, on the behalf of President and Fellows of Harvard College. All rights reserved. For Permissions, please email: journals. permissions@oup.com.

The Quarterly Journal of Economics (2012) 127, 283-331. doi:10.1093/qje/qjr048.

Advance Access publication on January 6, 2012. 
of the 20 major wars had significant economic causes, often related to conflict over resources. He emphasized "the rise of industrialism has led to the struggle for ... raw materials."

For example, in the War of the Pacific (1879-1884), Chile fought against a defensive alliance of Bolivia and Peru for the control of guano mineral deposits. The war was precipitated by the rise in the value of the deposits due to their extensive use in agriculture. Chile's victory increased the size of its treasury by $900 \%$.

Westing (1986) argues that many of the wars in the twentieth century had an important resource dimension. As examples he cites the Algerian War of Independence (1954-1962), the Six Day War (1967), and the Chaco War (1932-1935). ${ }^{2}$ More recently, Saddam Hussein's invasion of Kuwait in 1990 was a result of the dispute over the Rumaila oil field. In Resource Wars (2001), Klare argues that following the end of the Cold War, control of valuable natural resources has become increasingly important, and these resources will become a primary motivation for wars in the future. The famous Carter Doctrine, which states "Any attempt by any outside force to gain control of the Persian Gulf ... will be repelled by any means necessary, including military force," is just one facet of this perspective. ${ }^{3}$

This article develops an economic theory of resource wars and clarifies the conditions under which such wars can be prevented. We consider the dynamic interactions between a resource-rich and a resource-poor country, which enable us to capture the effect of the increasing scarcity of finite resources. Our approach combines the classic Hotelling (1931) model of exhaustible resources with a dynamic "guns and butter" model of armament and war along the lines of Powell (1993). A key friction in our model is the presence of

2. The Algerian War of Independence was fought partly because France was reluctant to lose Algeria's rich oil deposits. An important cause of the Six Day War between Israel and Arab states was the struggle for water resources of the Jordan River and other rivers in the area. The Chaco War was a successful war by Paraguay against Bolivia to annex the Gran Chaco area that was incorrectly thought to contain significant deposits of oil.

3. The Carter Doctrine was used in 1990 to justify the first Gulf War. Following the oil shocks in the 1970s, Secretary of State Henry Kissinger told the editors of Business Week that the United States was prepared to go to war over oil and that Washington would have no hesitation to use force "where there's some actual strangulation of the industrialized world." Klare (2001) argues that the Caspian Basin and the South China Sea are the most likely regions to witness large-scale warfare over oil in the future. War over water is another pressing issue in international politics. For example, in 1980 Boutros Boutros-Ghali commented that "The next war in our region will be over the waters of the Nile, not politics." 
limited commitment as countries cannot commit to future policies and transfers. We use the model to ask three main questions. First, what is the effect of resource scarcity on the likelihood of war? Second, how does the threat of war affect resource extraction and prices? Finally, how are resource wars and the dynamics of resource extraction affected by market structure?

In our framework, the resource-poor country (country $A$ ) exchanges a nonexhaustible good (a "consumption" good) for an exhaustible good with the resource-rich country (country $S$ ). At each date, country $A$ can arm and invade country $S$; higher armaments result in country $A$ capturing a greater portion of the remaining resources in country $S$. We consider two different market structures. In the first, the competitive environment, the stock of the exhaustible resource in country $S$ is distributed among a set of perfectly competitive price-taking firms that supply the world market. Country $A$ consumers purchase the resource at the world market price. If there is a war, then country $A$ captures part of the endowment and the rest of the stock is destroyed. In the second market structure, the monopolistic environment, the government of country $S$ regulates the price and the level of production of the resource (for example, by setting nonlinear taxes/tariffs). More specifically, following the armament decision by country $A$, country $S$ makes a take-it-or-leave-it price-quantity offer to country $A$, where country $A$ has the option of declaring war if this is preferable to accepting the offer. We characterize the equilibrium in Markovian strategies.

In both environments the elasticity of demand for resources plays a critical role in shaping war incentives. If this elasticity is below 1 , the value of the outstanding stock of resources rises as the resource is depleted and the incentives for country $A$ to arm and fight country $S$ rise over time. In contrast, if it is higher than 1 , the value of the outstanding stock of resources and country $A$ 's incentives to fight over these resources decline over time. For these reasons, the elasticity of demand will play a crucial role in the characterization of equilibrium dynamics. Given that empirically relevant estimates of elasticity for many resources are below 1, we focus our discussion on the implications of our model for elasticities below 1 (though we also provide the results for the converse case). ${ }^{4}$

4. Several studies estimate the short-run demand elasticity for oil to be between 0.01 and 0.1 , whereas the long-run elasticity is found to be higher but still less than 1 (see, for example, Gately and Huntington 2002). 
Our first main result is that a novel externality emerges in the competitive environment and can precipitate war. Specifically, firms in country $S$ do not internalize their impact on country $A$ 's war incentives. In the case with inelastic demand, firms do not take into account that their extraction decision increases country $A$ 's incentives to invade country $S$, because these incentives rise with resource scarcity. Moreover, if country $A$ is militarily sufficiently powerful (i.e., it can acquire a large enough portion of the outstanding resources during war), then country $A$ will eventually invade country $S$ once the stock of resources has been sufficiently depleted. Firms respond to the prospect of future war by increasing their extraction today, which in turn increases country A's incentives for war, thus leading to a pattern we refer to as the unraveling of peace. When there are no (binding) capacity constraints on resource extraction, an extreme form of unraveling of peace applies and there is a resource war in the initial period.

Motivated by the existence of this novel externality, the rest of the article studies whether regulation of prices and quantities by country $S$ acting as a monopolist, the "monopolistic environment," can mitigate this externality and prevent war. Our second main result shows that in some situations, regulation of prices and quantities by country $S$ 's government can prevent the realization of war, and this occurs through the introduction of intertemporal distortions. More specifically, if demand for the resource is inelastic, then resource extraction in the monopolistic environment occurs more slowly than that prescribed by the Hotelling rule (which is the rate of extraction in the competitive environment). This is because under inelastic demand, country A's armaments and incentives to declare war increase as the resource is depleted. Thus, country $S$ has an incentive to slow down the rate of extraction (relative to the Hotelling benchmark) so as to reduce the incentives for war and reduce the cost of armaments for which it is paying indirectly.

Interestingly, under some circumstances, regulation of prices and quantities by country $S$ can precipitate war in circumstances in which war is avoided in the competitive environment. This result emerges because of the presence of limited commitment. Specifically, because country $S$ cannot commit to a long-term contract with country $A$, country $A$ must arm in every period, even under peace, to enforce such a contract and obtain favorable terms of trade (in contrast, in the competitive environment country $A$ only arms if it is going to war). Because in the monopolistic 
environment country $S$ implicitly compensates country $A$ for the cost of this continual armament, if this cost of continually arming is sufficiently high, then this will induce war. ${ }^{5}$

Despite the importance of international conflict for economic and social outcomes and the often-hypothesized links between natural resources and international conflict, there are only a handful of papers discussing these issues. Our work is related to the literature on international wars that explores how countries bargain to avoid war (e.g., Powell 1993; Powell 1999; Schwarz and Sonin 2008; Skaperdas 1992; and Yared 2010). Our work builds on Schwarz and Sonin (2008) because we consider how international transfers can serve to sustain peace in a dynamic environment. The result that the lack of commitment to future transfers in the presence of armament can precipitate inefficient war in the monopolistic competition environment is related to several contributions in the literature on conflict (e.g., Powell 1993; Garfinkel and Skaperdas 2000; and McBride, Milante, and Skaperdas 2011). In contrast to this work, our focus is on the transfer of finite resources, and we study the two-way interaction between dynamic intertemporal resource allocation and the threat of war. ${ }^{6}$ In this context, our paper naturally builds on Hotelling's (1931) seminal work (see also Dasgupta and Heal 1979 and more recent contributions by Pindyck 1978 and Kremer and Morcom 2000).

Our work also contributes to the political economy of trade literature (e.g., Bagwell and Staiger 1990, 2001; Grossman and Helpman 1995; Maggi 1999; Maggi and Rodriguez-Clare 2007). Antrás and Padró i Miquel (2011) and Garfinkel, Skaperdas, and Syropoulos $(2009,2011)$ are most closely related. Antrás and Padró i Miquel study how a dominant country can affect its trading partner's domestic politics to influence the terms of trade. Garfinkel, Skaperdas, and Syropoulos (2009, 2011) combine a standard trade model with a contest function for interstate disputes over resources. They show that conflict over resources affects the pattern of comparative advantage, and free trade may

5. This result is related to the fact that in dynamic guns and butter type models, like Powell (1993), countries may go to war to avoid having to incur the cost of future armament under peace.

6. For related work on bargaining in the shadow of conflict, see also Acemoglu and Robinson (2006), Anderlini, Gerardi, and Lagunoff (2010), Baliga and Sjöström (2004), Chassang and Padró i Miquel (2010), Dixit (1987), Esteban and Ray (2008), Fearon (1995), Garfinkel, Skaperdas, and Syropoulos (2009), Hirshleifer (1995), and Jackson and Morelli (2009). 
intensify armaments so much that autarky may be preferable to free trade.

Finally, our article is related to the literature on the political economy of natural resources (e.g., Ross 1999; Tornell and Lane 1999; Caselli 2006; Robinson and Torvik 2006; Egorov, Guriev, and Sonin 2009). Our work is also connected to the literature on resource extraction and possible nationalization (e.g., Long 1975; Bohn and Deacon 2000; and Engel and Fischer 2008). In contrast to this work, our focus is on the international dimension of conflict over resources and we abstract from domestic politics or insecure ownership rights.

The rest of the article is organized as follows. Section II describes the general environment. Section III describes the competitive environment and Section IV describes the monopolistic environment. Section V describes two examples of resource wars to illustrate how the insights generated by our model are useful for interpreting these conflicts. Section VI considers various extensions. Section VII concludes and the Online Appendix includes additional proofs not included in the text.

\section{ENVIRONMENT}

Time is discrete and denoted by $t=0, \ldots, \infty$. There are two countries, $A$ and $S$, and two goods, an exhaustible resource and a perishable (nonresource) consumption good. Each country is inhabited by a continuum of mass 1 of identical households (or alternatively, by a representative household). We assume that the governments in both countries maximize the intertemporal utility of their citizens (of the representative household in their country). In view of this, we refer to actions by governments and countries interchangeably.

Households in country $A$ receive the following instantaneous utility from their consumption of the resource and the consumption good:

$$
u\left(x_{t}^{A}\right)+c_{t}^{A},
$$

where $x_{t}^{A} \geq 0$ corresponds to their consumption of the resource and $c_{t}^{A} \gtreqless 0$ refers to the consumption good. The utility function $u(\cdot)$ is strictly increasing and concave, $u^{\prime}(\cdot)>0$ and $u^{\prime \prime}(\cdot)<0$, and satisfies the following Inada conditions: $\lim _{x \rightarrow 0} u^{\prime}(x)=\infty$ and $\lim _{x \rightarrow \infty} u^{\prime}(x)=0$. For simplicity, we assume that households in country $S$ do not value the resource, and thus their utility is derived only from the consumption good: 


$$
c_{t}^{S}
$$

where $c_{t}^{S} \gtreqless 0$ refers to the consumption good. Households in both countries have a common discount factor $\beta \in(0,1)$.

In each period both countries are endowed with an exogenous perishable amount of the consumption good. We normalize the endowment of this good for each country to zero (recall that negative consumption is allowed). In addition, country $S$ is endowed with $e_{0}>0$ units of the exhaustible resource in period 0 . We assume that the amount extracted is nonstorable and has to be consumed in the same period, which prevents country $S$ from "selling the stock" of the resource. We denote by $x_{t} \geq 0$ the amount of extraction of the resource in period $t$. The remaining stock of the nonextracted resource in period $t+1, e_{t+1}$, follows the law of motion

$$
e_{t+1}=e_{t}-x_{t}
$$

The extraction of $x_{t}$ is costless but is limited by some (global) capacity constraint $\bar{x}>0$. In the text, we focus on the case in which capacity constraints never bind (e.g., $\bar{x}=\infty$ ) and we discuss how these results are modified once capacity constraints begin to bind.

Country $S$ extracts the resource and trades it for the consumption good with country $A$. We consider several trade environments in Sections III and IV.

In addition to trading, we allow country $A$ to make two additional decisions in each period: how much to arm and whether to declare war against country $S$. The armament technology works as follows. At every date $t$, country $A$ can choose a level of armament $m_{t} \in[0, \bar{m}]$, which has a per capita cost of $l\left(m_{t}\right)$ units of the consumption good. We assume that $l(\cdot)$ satisfies $l^{\prime}(\cdot)>$ $0, l^{\prime \prime}(\cdot) \geq 0$, and $l(0)=0$. The payoff from war depends on the amount of armament. If country $A$ has armament $m_{t}$ and attacks country $S$ that has $e_{t}$ units of the resource, it obtains fraction $w\left(m_{t}\right)$ of $e_{t}$, and the remaining fraction $1-w\left(m_{t}\right)$ is destroyed. ${ }^{7}$

7. To facilitate interpretation, we model the outcome of war as deterministicin particular, with country $A$ grabbing a fixed fraction of the resource. This is largely without loss of any generality. All of our results apply to an environment in which the outcome of war is stochastic, provided that after war the two countries never interact again. For example, we can define $w\left(m_{t}\right)$ as the probability that country $A$ receives a fraction $\lambda^{H}$ of the endowment and $1-w\left(m_{t}\right)$ as the probability that it receives a fraction $\lambda^{L}<\lambda^{H}$ of the endowment. 
We assume that $w(\cdot)$ satisfies $w^{\prime}(\cdot)>0, w^{\prime \prime}(\cdot) \leq 0, w(m) \in[0,1]$ for all $m$ with $w(0)=0$ and $\lim _{m \rightarrow \bar{m}} w^{\prime}(m)=0$, which imposes sufficient diminishing returns to armaments to ensure an interior level of equilibrium armaments. In most of the analysis, we allow for $\bar{m}=\infty$, in which case, $m_{t} \in[0, \infty)$ and $\lim _{m \rightarrow \infty} w^{\prime}(m)=0$. We use an indicator variable $f_{T}=0$ to denote that no war has occurred in periods $t=0, \ldots, T$ and $f_{T}=1$ to denote that war has occurred in some period $t \leq T$.

If country $A$, after choosing $m_{t}$ units of armament, attacks country $S$ and the remaining endowment is $e_{t}$, then the payoff to country $A$ is $V\left(w\left(m_{t}\right) e_{t}\right)-l\left(m_{t}\right)$, where $l\left(m_{t}\right)$ is the cost of armament incurred by the representative household in terms of the consumption good, and $V\left(w\left(m_{t}\right) e_{t}\right)$ is the continuation value of the representative household in that country starting with the ownership of the resource endowment of $w\left(m_{t}\right) e_{t}$ (because after war the ownership of a fraction $w\left(m_{t}\right)$ of the remaining resource is transferred to the country $A$ government). Since the government will use this stock to maximize the utility of its citizens, we have

$$
V\left(w\left(m_{t}\right) e_{t}\right)=\max _{\left\{x_{t+k}, e_{t+k+1}\right\}_{k=0}^{\infty}} \sum_{k=0}^{\infty} \beta^{k} u\left(x_{t+k}\right),
$$

subject to the resource and nonnegativity constraints, that is,

$$
\begin{gathered}
e_{t+1+k}=e_{t+k}-x_{t+k} \text { for } k>0, \\
e_{t+1}=w\left(m_{t}\right) e_{t}-x_{t}, \text { and } \\
x_{t+k}, e_{t+k} \geq 0 \text { for } k \geq 0 .
\end{gathered}
$$

In the event of a war, the payoff to country $S$ is given by $\psi<0$. In what follows, we impose the following relatively weak condition on the utility function $u(\cdot)$ and on the extraction limit (without explicitly stating it).

\section{ASSUMPTION 1.}

1. There exists some $\underline{\sigma}>0$ such that $\frac{-u^{\prime}(x)}{\left(x u^{\prime \prime}(x)\right)} \geq \underline{\sigma}$ for all $x>0$.

2 . The capacity constraint $\bar{x}$ is such that $\left(1-\beta^{\underline{\sigma}}\right) e_{0}<\bar{x}$.

3 . The capacity constraint $\bar{x}$ is such that for any $w\left(m_{t}\right) e_{t} \leq e_{0}$, the solution to equation (4) subject to equations (5)-(7) involves $x_{t}<\bar{x}$. 
Assumptions 1.1 and 1.2 ensure that the value of equation (4) subject to equations (5)-(7) is finite (bounded from below) starting from any $w\left(m_{t}\right) e_{t}>0$. Without any restriction on $u(\cdot)$, any feasible solution might lead to value $-\infty .{ }^{8}$ Assumption 1.3 enables us to simplify the notation. The following lemma immediately follows from Assumptions 1.1 and 1.2 (proof omitted).

LEMMA 1. $V\left(w\left(m_{t}\right) e_{t}\right)$ is bounded from below for all $w\left(m_{t}\right) e_{t}>0$.

For future reference, it is also useful to define $m^{*}(e)$ as the optimal amount of armament for country $A$ if it attacks country $S$ when country $S$ has $e$ units of resource endowment. Namely:

$$
m^{*}(e) \equiv \arg \max _{m \geq 0} V(w(m) e)-l(m) .
$$

Given our assumptions on $u(\cdot), w(\cdot)$, and $l(\cdot)$ (in particular, the Inada conditions) as well as Assumption 1, it is straightforward to see that $m^{*}(e)$ is well defined, satisfies $m^{*}(e)>0$, and is a continuously differentiable function of $e$ for all $e>0$.

One of the key variables in our analysis will be the elasticity of demand defined as $\frac{-u^{\prime}(x)}{\left(x u^{\prime \prime}(x)\right)}$. For now we prove the following useful result about the relationship between the comparative statics of $m^{*}$ with respect to $e$ and the elasticity of demand, which we will use throughout the article.

Proposition 1. If $\frac{-u^{\prime}(x)}{\left(x u^{\prime \prime}(x)\right)}<1$, then $m^{* \prime}(e)<0$. Conversely, if $\frac{-u^{\prime}(x)}{\left(x u^{\prime \prime}(x)\right)}>1$, then $m^{* \prime}(e)>0$.

Proof. See the Online Appendix.

The elasticity of demand $\frac{-u^{\prime}(x)}{\left(x u^{\prime \prime}(x)\right)}$ captures the value of resource consumption (in terms of the nonresource good) as resource consumption declines. Intuitively, as resource consumption decreases its price increases. The elasticity of demand determines which of these two effects dominates in determining the value of resource consumption. When this elasticity is less than 1 , the price effect dominates and thus the overall value of resource consumption rises as the quantity consumed declines. From (4), the value of the resource endowment to country $A$ is also related to these competing effects. If the elasticity of demand is less than 1 , the marginal value of resource consumption, and thus the value

8. The high enough value of $\bar{x}$ guarantees that choosing $x_{t+k}=\left(\beta^{\sigma}\right)^{k}$ $(1-\beta \underline{\sigma}) w\left(m_{t}\right) e_{0}$ is feasible. 
to country $A$ of capturing a greater stock of the resource, is greater when the resource is more scarce. From (8), this implies that country $A$ will be willing to invest more in armaments to capture a larger fraction of the remaining resource endowment when there is less of it. The converse result contained in Proposition 1 has an analogous intuition.

\section{COMPETITIVE ENVIRONMENT}

We start by considering a competitive environment in which trade occurs at market clearing prices and both buyers and sellers take these prices as given. This environment allows us to highlight the key economic forces that determine incentives to fight and to illustrate the externalities in the competitive environment.

\section{III.A. Markov Perfect Competitive Equilibrium}

In the competitive environment, there is a unit measure of firms in country $S$. Each firm is labeled by $i$ and owns an equal fraction of the total natural resource endowment of country $S$. Firm $i$ extracts resources $x_{i t}^{S}$ and sells them in a competitive market at price $p_{t}$ in units of the consumption good. All profits are rebated to households of country $S$ as dividends. We next define a notion of competitive equilibrium for this environment. This definition requires some care, because producers in country $S$ are price takers, but they must also recognize the likelihood of war, which results from the strategic choices of the government of country $A$. We define the notion of equilibrium in two steps. First, we impose price taking and market clearing for all relevant Arrow-Debreu commodities, that is, for the resource at each date following any history (by Walras's law, this guarantees market clearing for the consumption good). Second, we study the problem of country $A$ taking the relationship between the probability of war and these prices as given.

Price taking implies that each firm $i$ in country $S$ chooses extraction plan $\left\{x_{i t}^{S}\right\}_{t=0}^{\infty}$ to maximize its expected profits at time $t=0$,

$$
\max _{\left\{x_{i t}^{S}\right\}_{t=0}^{\infty}} \mathbb{E}_{0} \sum_{t=0}^{\infty} \beta^{t} p_{t} x_{i t}^{S}
$$

subject to the constraints 


$$
\begin{gathered}
e_{i t+1}=e_{i t}-x_{i t}^{S} \text { if } f_{t}=0, \\
x_{i t}^{S}=0 \text { if } f_{t}=1, \text { and } \\
x_{i t}^{S}, e_{i t+1} \geq 0 \text { for all } t \geq 0 .
\end{gathered}
$$

The second constraint stems from the fact that firm $i$ loses its endowment if country $A$ declares war. The solution to this problem implies that, when $f_{t}=0$,

$$
x_{i t}^{S}\left\{\begin{array}{ll}
=0 & \text { if } p_{t}<\beta p_{t+1} \operatorname{Pr}\left\{f_{t+1}=0\right\} \\
\in\left[0, \min \left\{\bar{x}, e_{i t}\right\}\right] & \text { if } p_{t}=\beta p_{t+1} \operatorname{Pr}\left\{f_{t+1}=0\right\} \\
=\min \left\{\bar{x}, e_{i t}\right\} & \text { if } p_{t}>\beta p_{t+1} \operatorname{Pr}\left\{f_{t+1}=0\right\}
\end{array} .\right.
$$

Equation (10) captures the fact that firms take into account not only future prices but also the future probability of war in deciding how much to extract today. It also incorporates the fact that the extraction limit $\bar{x}$ will not bind when the endowment of firms $e_{i t}$ is less than $\bar{x}$.

Similarly, the representative household in country $A$ chooses the demand for resource $x_{t}^{A}$ as a solution to

$$
\max _{x_{t}^{A} \geq 0} u\left(x_{t}^{A}\right)-p_{t} x_{t}^{A},
$$

which gives us the standard optimality condition

$$
u^{\prime}\left(x_{t}^{A}\right)=p_{t} .
$$

We denote the total supply of the resource by $x_{t}^{S}$. Market clearing implies that the price sequence $\left\{p_{t}\right\}_{t=0}^{\infty}$ must be such that

$$
x_{t}^{S}=x_{t}^{A}
$$

for all $t$.

In addition, the country $A$ government can impose a lumpsum tax on its citizens of size $l\left(m_{t}\right)$ to invest in armament $m_{t}$, and it can choose to attack country $S$ at any date.

More specifically, we consider the following sequence of events. Because the game is trivial after the war has occurred, we only focus on the histories for which war has not occurred yet (i.e., on histories where $f_{t-1}=0$ ).

1. Country A's government chooses a level of armament $m_{t} \geq 0$. 
2. Firms in country $S$ commit to extraction $x_{t}^{S} \geq 0$ and households in country $A$ commit to consumption $x_{t}^{A}$ at prices $p_{t}$ in the event that country $A$ does not attack country $S$ at stage 3.

3. Country A's government decides whether to attack country $S$.

4. Extraction and consumption take place.

Note that in stage 2, firms and households trade contingent claims on the resource (i.e., contingent on whether war is declared at stage 3$)^{9}$

We can now define a Markov perfect competitive equilibrium (MPCE) formally. For the same reason that the game is trivial after war has occurred, we only define strategies for dates $t$ for which $f_{t-1}=0$. Denote the strategy of the government of country $A$ as $\varphi$, which consists of a pair of functions $\varphi^{m}$ and $\varphi^{f}$. In each period, the function $\varphi^{m}$ assigns a probability distribution over armament decisions $m_{t}$ as a function of $e_{t}$. The function $\varphi^{f}$ assigns a probability distribution with which country $S$ attacks as a function of $\left(e_{t}, m_{t}, p_{t}, x_{t}^{S}, x_{t}^{A}\right) .{ }^{10}$

Firms and households take the sequences of prices and policies by the government of country $A$ as given. It is important to note that because we are focusing on Markov perfect equilibria, even if war is expected with probability 1 at date $t$, their choices do take into account the continuation strategy of the government and the future sequence of prices from $t+1$ onward in the event that war is not actually declared at $t$. Therefore, allocations and prices conditional on war never being declared need to be specified as part of the equilibrium. To do this, let us define a sequence $\gamma \equiv\left\{e_{t}^{*}, p_{t}^{*}, x_{t}^{S *}, x_{t}^{A *}\right\}_{t=0}^{\infty}$, where each element at $t$ corresponds to the values of $\left(e_{t}, p_{t}, x_{t}^{S}, x_{t}^{A}\right)$ which would emerge if $f_{t-1}=0$. Given such a sequence $\gamma$, one can define $U_{A}\left(e_{t}^{*}\right)$ as the welfare of (the representative household in) country $A$ starting from $e_{t}^{*}$

9. We could alternatively simplify the timing of the game by allowing country $A$ to arm and to make its attacking decisions in the first stage, and then, if the attack did not occur, households and firms would trade in the second stage. Under our notion of equilibrium, these two setups are equivalent. We chose this setup to be consistent with the timing of the game in Section IV.

10. Throughout the article we focus on Markovian equilibria for two reasons. First, we believe that these capture the main commitment problems shaping economic incentives in a clean and economical manner. Second, as we explain further in Section VI.C. , even though the structure of subgame perfect equilibria appears similar, a tight characterization of the set of these equilibria is challenging. 
conditional on $f_{t-1}=0$. Given this definition, the period $t$ payoff to country $A$, starting from $e_{t}^{*}$ under $f_{t-1}=0$ and conditional on some choice $\left(m_{t}, f_{t}\right)$, is

$$
\left(1-f_{t}\right)\left(u\left(x_{t}^{A *}\right)-p_{t}^{*} x_{t}^{A *}+\beta U_{A}\left(e_{t+1}^{*}\right)\right)+f_{t} V\left(w\left(m_{t}\right) e_{t}^{*}\right)-l\left(m_{t}\right) .
$$

The first term is the value in case of no war, and the second term is the continuation value following war.

Before providing a formal definition, we also note a potential source of uninteresting multiplicity in this environment. Consider a situation in which $e_{t}=0$. If $u(0)$ is finite, then country $A$ would be indifferent between choosing $f_{t}=0$ on the one hand and $m_{t}=0$ and $f_{t}=1$ on the other. Moreover, if $u(0)=-\infty$, then country $A$ 's strategy is not well defined. Depending on which action country $A$ chooses at zero endowment, one can then change incentives at earlier stages and construct different equilibria. We choose a solution that deals with both of these issues simultaneously where the details are discussed in the Online Appendix. Specifically, we focus on a refinement of equilibria where war decisions at all $e_{t}$ are optimal in the presence of an additive cost of war equal to $v>0$ for country $A$. In that case, the expressions we have here correspond to the limiting economy where $v \rightarrow 0$ (in the Online Appendix, we analyze the problem for an arbitrary $v>0$; focusing on $v \rightarrow 0$ in the text simplifies expressions). Moreover, we impose that war decisions at $e_{t}=0$ are consistent with war decisions for an arbitrarily small endowment (in the limit, zero endowment). The presence of the additive cost of war $v$ implies that war never occurs at $e_{t}=0$ if $u(0)$ is finite, though it is still the case that war may occur at $e_{t}=0$ if $u(0)=-\infty$ depending on the limiting behavior of war incentives. Throughout, MPCE refers to such "refined" equilibria (without this qualifier) as defined next. ${ }^{11}$

DEFINITION 1. An MPCE consists of $\varphi$ and $\gamma$ such that at each $t$ :

1. $\varphi^{m}$ maximizes equation (14) for every $e_{t}^{*}>0$ in $\gamma$.

2. $\varphi^{f}$ maximizes equation (14) given $m_{t}$ for every $\left(e_{t}^{*}, p_{t}^{*}, x_{t}^{S *}\right.$, $\left.x_{t}^{A *}\right)$ with $e_{t}^{*}>0$ in $\gamma$.

3. $\gamma$ satisfies equations (3), (10), (12), and (13) with $\operatorname{Pr}\left\{f_{t+1}=1\right\}=\varphi^{f}\left(e_{t+1}^{*}, m_{t+1}^{*}, p_{t+1}^{*}, x_{t+1}^{S *}, x_{t+1}^{A *}\right)$.

11. Put differently, this refinement is in the spirit of "trembling hand perfection" and rules out equilibria supported by weakly dominated strategies for country $A$. 
4. If $e_{t}^{*}=0$, then $\varphi\left(e_{t}^{*}\right)=\lim _{e \rightarrow 0} \varphi_{v}(e)$ where $\varphi_{v}(e)$ denotes the strategy for country $A$ that maximizes (14) for some cost of war $v>0$.

The first three requirements are standard. They ensure that the government in country $A$ makes its armament and fighting decisions optimally today, taking into account its future behavior and that of the private sector in the event that war is not declared today. Furthermore, firms and households behave optimally today, taking into account the future behavior of the government in the event that war is not declared today. They also impose that the continuation equilibrium in the event that war does not happen today must always be such that households and firms optimize, markets clear, and country $A$ chooses its best response. The fourth requirement is the refinement we mentioned. It imposes that best response for country $A$ (and in particular its war decision) at zero endowment is the limit of best responses in the perturbed economy as the endowment approaches zero. The fact that this needs to be the case for some $v>0$ (rather than for all $v$ or for some specific value) makes this a weaker refinement that is nonetheless sufficient for our purposes, and in the Online Appendix we analyze the problem for an arbitrary $v>0$ which applies at all $e_{t}$.

\section{III.B. Analysis without Capacity Constraints}

We next characterize MPCEs and begin by focusing on the case with no capacity constraints with $\bar{x}=\infty$. Our first result establishes the existence of MPCE in this environment.

LEMMA 2. An MPCE exists.

Proof. See the Online Appendix.

As a benchmark, let us first consider a case when country $A$ cannot arm and declare war-that is, focus on the case where $f_{t}=0$ for all $t$. In that case there is no uncertainty and the first-order conditions to (10), (12), and (13) imply that the equilibrium prices $p_{t}$ must satisfy

$$
\beta p_{t+1}=p_{t} .
$$

This is a market form of the famous Hotelling rule and requires that prices of the exhaustible resource grow at the rate of interests, which is also equal to the discount rate, $\frac{(1-\beta)}{\beta}$. The 
intuition is straightforward: because producers are price-takers and can extract the resource at no cost, there will only be positive extraction at all dates if they make the same discounted profits by extracting at any date, which implies (15). Moreover, given the Inada conditions on the utility function and the first-order condition (12), zero extraction at any date is not consistent with equilibrium. Hence (15) must hold in any MPCE.

The connection between (15) and the Hotelling rule can be seen more explicitly by using (10), (12), and (13), which imply that the sequence of resource consumption $\left\{x_{t}\right\}_{t=0}^{\infty}$ must satisfy

$$
\beta u^{\prime}\left(x_{t+1}\right)=u^{\prime}\left(x_{t}\right)
$$

at all $t$, which is the familiar form of the Hotelling rule (with zero extraction costs).

We next turn to country $A$ 's armament and war decisions and characterize MPCE. We first consider pure-strategy equilibria (where $\varphi^{f}$ is either 0 or 1 at each date). We will see that in this case war cannot be delayed because of the externalities that the production decisions of price-taking firms create on other firms.

PROPOSITION 2. In any pure-strategy MPCE:

1. War can only occur at $t=0$ along the equilibrium path.

2. The equilibrium sequence of resource extraction, $x_{t}$, satisfies (16) for all $t$.

Proof. Suppose country $A$ attacks at date $T>0$ with probability 1. From (10), firms extract all the resource before date $T$, so that $e_{t}=0$ for some $t \leq T$. This implies that $x_{T}=0$. We now show that there is necessarily a deviation that is strictly profitable. Consider two cases. First, suppose $u(0)$ is finite. In this case, the fourth requirement of the definition of MPCE implies that an allocation in which country $A$ attacks at $T$ cannot be an equilibrium, yielding a contradiction. Second, suppose that $u(0)=-\infty$ and let the date at which the endowment is depleted be $t \geq 1$, which implies that $e_{t-1}>0$. In this case the equilibrium payoff for country $A$ from the viewpoint of date $t-1$ is $-\infty$. Consider the following deviation: country $A$ chooses the level of armament $m^{*}\left(e_{t-1}\right)$ as given by (8), and attacks country $S$ at date $t-1$. This deviation has payoff

$$
V\left(w\left(m^{*}\left(e_{t-1}\right)\right) e_{t-1}\right)-l\left(m^{*}\left(e_{t-1}\right)\right)>-\infty,
$$

since $e_{t-1}>0$. This implies that war at $T$ cannot be a best response. Because this argument is true for any $T>0$, it must 
be that any war can only occur at date $t=0$. This establishes the first part of the proposition.

To derive the second part, note that if a war occurs at time 0 , the first-order conditions to (4) imply that $x_{t}$ must satisfy (16). If no attack occurs at $t=0$, the first part implies that $f_{t}=0$ for all $t$ and the argument preceding the proposition establishes (16).

This proposition shows that in pure-strategy equilibria wars cannot be delayed. The intuition is simple and directly related to the externalities across firms: if there is a war at time $T$, price-taking firms will deplete their entire endowment before $T$, and this will encourage war to be declared earlier. This result illustrates a more general effect that we refer to as the unraveling of peace: the anticipation of future war encourages earlier extraction, which in turn causes earlier war. We will see that this effect is also present with capacity constraints, even though war will no longer take place in the initial period in this case.

Though the fact that country $S$ firms fail to internalize their impact on future war decisions is at the heart of Proposition 2, lack of commitment by country $A$ also plays a role. More specifically, country $A$ 's armament and war decisions are chosen to maximize (4) at each date. Therefore, the unraveling of peace and war at date 0 occurs because country $A$ would otherwise optimally choose to go to war at some future date $T$. Suppose that country $A$ 's consumers are strictly better off at time $t=0$ under permanent peace than under immediate war. In such a situation, country $A$ 's government could make its citizens better off by committing at $t=0$ to not going to war in the future. Not only would this commitment prevent the unraveling of peace, but it would also make country $S$ households strictly better off because they would be receiving positive payments from country $A$ instead of receiving the payoff $\psi<0$ from war.

Proposition 2 also implies that along the equilibrium path, consumption of the resource satisfies the Hotelling rule, (16), and that there are no intertemporal distortions. If there is no war at $t=0$, then the equilibrium is identical to the benchmark competitive equilibrium in which war is not possible. If there is war at $t=0$, then country $A$ seizes a fraction $w\left(m^{*}\left(e_{0}\right)\right)$ of the initial endowment and it extracts resources according to (16) because this maximizes the welfare of households in country $A$.

To further characterize under which conditions wars may occur and to explore the possibility of mixed-strategy equilibria, 
we restrict attention to utility functions that imply a constant elasticity of demand for the resource. This is the same as the commonly used class of constant relative risk aversion (CRRA) or iso-elastic preferences:

$$
u(x)=\frac{x^{1-\frac{1}{\sigma}}-1}{1-\frac{1}{\sigma}}
$$

for $\sigma>0$. Clearly, the elasticity of demand for the exhaustible resource is constant and equal to $\frac{-u^{\prime}(x)}{\left(x u^{\prime \prime}(x)\right)}=\sigma$. As we will see, when $\sigma<1$, which is the empirically relevant case for oil (and perhaps also for other exhaustible resources), total spending on the exhaustible resource increases over time as its endowment is depleted-because the price increase dominates the reduction in quantity. When preferences take this form, we can generalize Proposition 2 to any MPCE (i.e., also those in mixed strategies) provided that $\sigma \nRightarrow 1$.

Proposition 3. Suppose $u(x)$ satisfies (17) and $\sigma \nRightarrow 1$. Then in any mixed-strategy MPCE:

1. War can only occur at $t=0$.

2 . The equilibrium sequence of resource extraction, $x_{t}$, satisfies (16) for all $t$.

Proof. See the Online Appendix.

To understand the intuition for this proposition it is useful to consider how country $A$ 's incentives to declare war change over time as the endowment of the exhaustible resource declines. To do this, consider the special case where $w(\cdot)$ is a step function. In particular, if country $A$ invests $\tilde{m}>0$ in armament, it will receive the entire remaining endowment of the exhaustible resource, that is, $w(\tilde{m})=1$. If it invests less, it will obtain none of the endowment. This functional form implies that country $A$ is effectively choosing between zero armaments (and no war), and armaments equal to $\tilde{m}$ to obtain the entire endowment of the resource. Suppose further that country $A$ is choosing between going to war at time $t$ and permanent peace thereafter. Thus if it does not declare war at time $t$ starting from some endowment $e_{t}$, the subsequent allocations are given by the standard competitive equilibrium allocations, denoted by $\left\{\widetilde{x}_{t+k}\left(e_{t}\right), \widetilde{p}_{t+k}\left(e_{t}\right), \widetilde{e}_{t+k}\left(e_{t}\right)\right\}_{k=0}^{\infty}$. It is straightforward to show that $\widetilde{x}_{t+k}\left(e_{t}\right)=\left(1-\beta^{\sigma}\right) \widetilde{e}_{t+k}\left(e_{t}\right), \widetilde{p}_{t+k}\left(e_{t}\right)=\left(\widetilde{x}_{t+k}\left(e_{t}\right)\right)^{\frac{-1}{\sigma}}$, and $\widetilde{e}_{t+k+1}\left(e_{t}\right)=\widetilde{e}_{t+k}\left(e_{t}\right)-\widetilde{x}_{t+k}\left(e_{t}\right)$. This implies that the payoff to country 
$A$ in period $t$ from not going to war is equal to

$$
\begin{aligned}
U^{C}\left(e_{t}\right) & =\sum_{k=0}^{\infty} \beta^{k} u\left(\widetilde{x}_{t+k}\left(e_{t}\right)\right)-\sum_{k=0}^{\infty} \beta^{k} \widetilde{p}_{t+k}\left(e_{t}\right) \widetilde{x}_{t+k}\left(e_{t}\right) \\
& =\sum_{k=0}^{\infty} \beta^{k} u\left(\widetilde{x}_{t+k}\left(e_{t}\right)\right)-\left(1-\beta^{\sigma}\right)^{-\frac{1}{\sigma}} e_{t}^{1-\frac{1}{\sigma}} .
\end{aligned}
$$

If country $A$ invests $\tilde{m}$ in armament in period $t$ and declares war, then, because $w(\tilde{m})=1$, its payoff is given by

$$
V\left(w(\tilde{m}) e_{t}\right)-l(\tilde{m})=\sum_{k=0}^{\infty} \beta^{k} u\left(\tilde{x}_{t+k}\left(e_{t}\right)\right)-l(\tilde{m}) .
$$

This implies that the difference between the payoffs from war and no war is equal to

$$
V\left(w(\tilde{m}) e_{t}\right)-l(\tilde{m})-U^{C}\left(e_{t}\right)=\left(1-\beta^{\sigma}\right)^{-\frac{1}{\sigma}} e_{t}^{1-\frac{1}{\sigma}}-l(\tilde{m}) .
$$

Since $\left\{e_{t}\right\}_{t=0}^{\infty}$ is a decreasing sequence by construction, this expression monotonically decreases to 0 if $\sigma$ is greater than 1 and increases toward infinity if $\sigma$ is less than 1 . Therefore, depending on the elasticity of demand for the resource, the payoff from war either monotonically converges to 0 or becomes unbounded. Which of these two cases applies depends on whether the payments that country $A$ makes to country $S$ in competitive equilibrium, $\sum_{k=0}^{\infty} \beta^{k} \widetilde{p}_{t+k}\left(e_{t}\right) \widetilde{x}_{t+k}\left(e_{t}\right)$, converge to 0 or infinity as $e_{t}$ declines. This logic allows us to show in the proof of Proposition 3 that if demand is elastic ( $\sigma$ is greater than 1), incentives to fight must be decreasing for country $A$. In particular, if it weakly prefers peace to war in any period $t$, it strictly prefers peace in all the subsequent periods. Alternatively, if the demand for the resource is inelastic ( $\sigma$ is less than 1), incentives to fight must be increasing and country $A$ eventually prefers war, in which case the arguments of Proposition 2 apply directly. In particular, in this case war must occur with probability 1 independently of the cost of armaments $l(\tilde{m})$ and the cost of war to country $S$. It can be shown that the same conclusion holds if country $A$ could, as in our model, choose to go to war at any date it wishes.

This special case illustrates the key intuition underlying Proposition 3. More generally, war has an additional cost for country $A$, which is that a fraction $1-w\left(m^{*}(e)\right)$ of the endowment is lost in war. If this cost is sufficiently high, country $A$ may 
prefer not to attack country $S$ even if its equilibrium payments $\sum_{k=0}^{\infty} \beta^{k} \widetilde{p}_{t+k}\left(e_{t}\right) \widetilde{x}_{t+k}\left(e_{t}\right)$ diverge to infinity. All the same, the main insights and the factors affecting the comparison between war and no war remain the same as in the case where $w(\tilde{m})=1$.

The next proposition contains the main result for the competitive environment. It characterizes the conditions under which equilibrium involves war.

Proposition 4. Suppose $u(x)$ satisfies (17) and $\sigma \neq 1$.

1. Suppose $\sigma>1$. Then there exists $\widehat{e}>0$ such that if $e_{0}<\hat{e}$, then the unique MPCE has permanent peace, and if $e_{0}>\widehat{e}$, then in any MPCE war occurs in period 0 with probability 1.

2. Suppose $\sigma<1$. Then there exists $\widehat{w}<1$ such that if $\lim _{m \rightarrow \bar{m}} w(m)<\widehat{w}$, then the unique MPCE has permanent peace, and if $\lim _{m \rightarrow \bar{m}} w(m)>\widehat{w}$, then in any MPCE war occurs in period 0 with probability 1 .

Proof. See the Online Appendix.

In the empirically more relevant case where $\sigma<1$, provided that country $A$ is capable of capturing a sufficiently high fraction of the remaining endowment of the resource, the equilibrium involves war at the initial date. The intuition for this result follows from Proposition 3. When $\sigma<1$, spending on the resource and incentives to declare war increase over time. If, by spending the necessary resources, country $A$ can capture a sufficient fraction of the remaining endowment of the resource (i.e., if $\lim _{m \rightarrow \bar{m}} w(m)>$ $\widehat{w})$, then it will necessarily find it optimal to declare war at some point. But we know from Proposition 3 that war must occur, if at all, in the initial period, so in this case, country $A$ will declare war at the initial date.

Notably, this conclusion is independent of the costs of war to either country (i.e., the function $l(\cdot)$ for country $A$, and $-\psi$ for country $S$ ). In particular, this proposition applies even if $\psi=-\infty$. In this case, of course, war is extremely costly to the citizens of country $S$, but under our assumption that resource extraction takes place competitively, firms in this country can take no action to stave off a very costly war. This is one of the main motivations for our analysis of the "monopolistic" environment, where such actions will be possible. For future reference, we state this simple implication of Proposition 4 as a corollary. 
CoROLlaRY 1. If $\sigma<1$ and if $\lim _{m \rightarrow \bar{m}} w(m)$ is sufficiently close to 1 , then war will take place at date 0 even if $\psi=-\infty$.

Propositions 3 and 4 do not cover the knife-edge case where $\sigma=1$, which turns out to be more complicated. When $\sigma=1$, the demand for the resource has unitary elasticity and the equilibrium payment $p_{t} x_{t}$ is constant over time (independent of $e_{t}$ ). In this case, when there exists a pure-strategy equilibrium with no war, there also exist mixed-strategy equilibria. In particular, country $A$ might mix with a constant probability between war and no war at each date. When such a mixed-strategy equilibrium exists, it will involve equilibrium prices that rise at a faster rate than $\frac{(1-\beta)}{\beta}$, and thus equilibrium allocations and prices will deviate from the Hotelling rule (16). Since such equilibria are only possible in the knife-edge case where $\sigma=1$, we do not dwell on them.

\section{III.C. Analysis with Capacity Constraints}

We now consider the case with capacity constraints (e.g., $\bar{x}<\infty)$. If country $A$ does not arm or declare war, then analogous arguments as in the previous section imply that (15) and (16) are replaced with the following two equations:

$$
\begin{aligned}
\beta p_{t+1} & \leq p_{t}, \text { and } \\
\beta u^{\prime}\left(x_{t+1}\right) & \leq u^{\prime}\left(x_{t}\right),
\end{aligned}
$$

where both of these hold as equality if $x_{t}<\bar{x}$. The intuition behind the Hotelling rule under capacity constraints is analogous to that without capacity constraints with the exception that it takes into account that prices could grow strictly slower than the rate of interest when capacity constraints are binding. Assumption 1.3 implies that the constraint $x_{t} \leq \bar{x}$ does not bind in a competitive equilibrium in which country $A$ does not arm or declare war, so that both (18) and (19) hold with equality.

Although a general characterization of equilibria with armament and potential war is difficult in the presence of capacity constraints, the following proposition characterizes the conditions under which war occurs under inelastic preferences and the transition path to war in this equilibrium.

Proposition 5. Suppose there exists some $\bar{\sigma}<1$ such that $\frac{-u^{\prime}(x)}{\left(x u^{\prime \prime}(x)\right)} \leq \bar{\sigma}$ for all $x>0$, and suppose that $\lim _{m \rightarrow \bar{m}} w(m)$ is sufficiently close to 1 . Then 
1. An MPCE exists.

2. In any MPCE, war occurs with probability 1 before some $T<\infty$, and $x_{t}=\bar{x}$ if war has not yet occurred (i.e., if $\left.f_{t}=0\right)$.

3. If $\bar{x}>e_{0}$, then war occurs in period 0 .

Proof. See the Online Appendix.

This proposition thus shows that war is still inevitable when demand is inelastic and country $A$ can capture most of the remaining endowment of the resource. The intuition for this result is analogous to Proposition 4. Because demand is inelastic, spending on the resource and incentives to declare war increase over time. If, by spending the necessary resources, country $A$ can capture a sufficient fraction of the remaining endowment of the resource, then it will necessarily find it optimal to declare war at some point. Moreover, the last part of the proposition shows that if initially the capacity constraint is not binding, war will occur at date $t=0$.

In contrast to the case without capacity constraints, firms in country $S$ cannot extract the entire endowment even when they anticipate war. This in turn may encourage country $A$ to delay the onset of war. Nevertheless, a similar unraveling of peace result still holds in this case. Country $S$ producers extract resources faster than they would otherwise, and in fact, until the war occurs, they extract resources at capacity, so that $p_{t}=u^{\prime}(\bar{x})$ for all $t$ until war takes place at some $T<\infty$. The fact that there is rapid extraction of resources then determines the timing of war, $T{ }^{12}$ More specifically, on the one hand, country $A$ may prefer an earlier war because this avoids the excessively rapid depletion of the resource until war; on the other hand, it may prefer a later war because this postpones the costs of armaments and resource destruction. $^{13}$

12. It is also worth noting that similar results also apply when there are convex extraction costs captured by some function $\Gamma(x)$. In this case, it can be shown that Proposition 5 holds for an endogenously determined $\bar{x}$ defined as the solution to $u^{\prime}(\bar{x})=\Gamma^{\prime}(\bar{x})$. Details are available from the authors on request.

13. The presence of these two effects imply that the timing of war $T$ is nonmonotonic in the capacity constraint $\bar{x}$. An increase in $\bar{x}$ can induce earlier war through the first effect or later war through the second. It is possible to construct examples in which the first or the second effect dominates. Details available on request. 


\section{MONOPOLISTIC ENVIRONMENT}

From the point of view of country $S$, the competitive equilibrium is suboptimal for two reasons. The first is the standard price effect. Each producer, by extracting more, is reducing the price faced by other producers. In standard trade models, this price effect is sometimes internalized by using "optimal" import and export taxes. The second is a novel distortion resulting from the military actions of country $A$ in response to the equilibrium path of prices. Recall the second part of Proposition 4 with $\sigma<1$ and Proposition 5; if $w(\bar{m})=1$, war is unavoidable under competitive markets even though the cost of war, $-\psi$, may be arbitrarily high for country $S$. In this case, war occurs because, as the price of the resource increases, payments from country $A$ households to country $S$ firms become arbitrarily large. Yet price-taking firms do not internalize that high resource prices increase incentives of country $A$ to declare war. If country $S$ could somehow reduce these payments, it may be able to avoid war. It may therefore find it beneficial to act as a monopolist and regulate the price and quantity of the resource. In this section, we study equilibrium allocations in such a monopolistic environment. We will see that by regulating the levels of prices and production, the government of country $S$ can indeed internalize the externalities, and a consequence of this will be deviations of prices from the Hotelling rule. However, this type of monopolistic behavior by country $S$ introduces a new externality due to its inability to commit to providing attractive terms of trade to country $A$. Consequently, even though the monopolistic environment may be more effective at preventing war under certain conditions, paradoxically it can also increase the likelihood of war and may even make country $S$ worse off under others, despite its ability to act as the monopolist (Stackelberg leader) in its interactions with country $A .{ }^{14}$

\section{IV.A. Timing of Events and Markov Perfect Monopolistic Equilibrium}

We model the regulation of prices and quantities by the country $S$ government simply by allowing it to act as a "monopolist"

14. Yet another alternative arrangement is one in which country $S$ is restricted to set the price of the resource but cannot distort extraction decisions. Clearly, such policies are a subset of the more general set of policies we consider in this section, which allow general nonlinear tariffs and thus permit country $S$ to choose any price-quantity combination. 
and set prices and quantities recognizing their implications for current and future economic and military actions. In particular, suppose that the government sets nonlinear tariffs to control both the level of the price of the resource and its production. Given this resulting price-quantity pair, country $A$ can still declare war. This environment is equivalent to one in which country $S$ makes a takeit-or-leave-it price-quantity offer to country $A$. In what follows, we directly study a game in which country $S$ makes such offers (and do not explicitly introduce the nonlinear tariffs to save on notation).

More specifically, we consider the following game. At every date $t$ at which war has not yet occurred, country $A$ chooses the level of armament $m_{t}$. Next, (the government of) country $S$ makes a take-it-or-leave-it offer $z_{t}=\left\{x_{t}^{o}, c_{t}^{o}\right\}$ to country $A$, consisting of an offered delivery of $x_{t}^{o}$ units of the resource in exchange for $-c_{t}^{o}$ units of the consumption good. Country $A$ then accepts or rejects this offer, which is denoted by $a_{t}=\{0,1\}$, with $a_{t}=1$ corresponding to acceptance. Conditional on rejecting the offer, country $A$ then chooses whether to declare war on country $S$. As in Section III, the continuation payoff to country $A$ following war is $V\left(w\left(m_{t}\right) e_{t}\right)-$ $l\left(m_{t}\right)$, and the continuation payoff for country $S$ is $\psi \cdot{ }^{15}$ If country $A$ accepts the offer, then the instantaneous utilities to households in countries $A$ and $S$ are $u\left(x_{t}^{o}\right)+c_{t}^{o}-l\left(m_{t}\right)$ and $-c_{t}^{o}$, respectively. If instead country $A$ rejects the offer and does not declare war, then the instantaneous utilities to households in country $A$ and $S$ are $u(0)-l\left(m_{t}\right)$ and 0 , respectively.

We formally summarize the order of events for all periods $t$ for which $f_{t-1}=0$ as follows:

1. Country A's government chooses a level of armament $m_{t}$.

2. Country $S$ 's government makes a take-it-or-leave-it offer $z_{t}$ to country $A$.

3. Country A's government decides whether to accept the offer $a_{t}$. If $a_{t}=0$, it can declare war by choosing $f_{t}$.

4. Extraction and consumption take place.

The timing of events makes it clear that this is a dynamic game between the two countries. We consider its Markov perfect equilibrium, which we refer to as Markov perfect monopolistic

15. The additional cost of war $v$ introduced for the refinement of MPCE in the previous section is now taken to be small or zero, and does not play any role in the analysis. 
equilibrium (MPME). This equilibrium is similar to an MPCE with the exception that firm and consumer optimality is no longer required, since country $S$ 's and country $A$ 's governments jointly determine the transfer of goods across countries. In such an equilibrium all actions depend only on payoff relevant state variables, which here include the endowment, $e_{t}$, and prior actions at the same date. As we did in the analysis of MPCE, we define strategies for dates $t$ in which $f_{t-1}=0$ (i.e., for histories where war has not yet occurred).

Let country $A^{\prime}$ 's strategy be represented by $\phi_{A}=\left\{\phi_{A}^{m}, \phi_{A}^{a}, \phi_{A}^{f}\right\}$. Here $\phi_{A}^{m}$ assigns an armament decision for every $e_{t} ; \phi_{A}^{a}$ assigns an acceptance decision for every $\left(e_{t}, m_{t}, x_{t}^{o}, c_{t}^{o}\right)$; and $\phi_{A}^{f}$ assigns a war decision for every $\left(e_{t}, m_{t}, x_{t}^{o}, c_{t}^{o}, a_{t}\right)$, where this decision is constrained to 0 if $a_{t}=1$. Country $S$ 's strategy is denoted by $\phi_{S}$ and consists of an offer $z$ for every $\left(e_{t}, m_{t}\right)$. We allow mixed strategies for both countries, though it will become clear later that only pure strategies are relevant for all, except for knife-edge, cases. We next provide a formal definition of equilibrium.

DEFINITION 2. An (MPME) is a pair $\left\{\phi_{A}, \phi_{S}\right\}$ where

1. Given $\phi_{S}, \phi_{A}^{m}$ maximizes the welfare of country $A$ for every $e_{t}, \phi_{A}^{a}$ maximizes the welfare of country $A$ for every $\left(e_{t}, m_{t}, x_{t}^{o}, c_{t}^{o}\right)$, and $\phi_{A}^{f}$ maximizes the welfare of country $A$ for every $\left(e_{t}, m_{t}, x_{t}^{o}, c_{t}^{o}, a_{t}\right)$ subject to $f_{t}=0$ if $a_{t}=1$.

2. Given $\phi_{A}, \phi_{S}$ maximizes the welfare of country $S$ for every $\left(e_{t}, m_{t}\right)$ subject to equation (3).

Given these strategies, we define the equilibrium continuation values $\left\{U_{A}\left(e_{t}\right), U_{S}\left(e_{t}\right)\right\}$ as the continuation values to countries $A$ and $S$, respectively, at the beginning of the stage game at $t$ conditional on no war in the past. Similar to equation (14) in the previous section, these continuation values are given by

$$
\begin{aligned}
U_{A}\left(e_{t}\right) & =\left(1-f_{t}\right)\left(u\left(x_{t}\right)+c_{t}+\beta U_{A}\left(e_{t+1}\right)\right)+f_{t} V\left(w\left(m_{t}\right) e_{t}\right)-l\left(m_{t}\right), \text { and } \\
U_{S}\left(e_{t}\right) & =\left(1-f_{t}\right)\left(-c_{t}+\beta U_{S}\left(e_{t+1}\right)\right)+f_{t} \psi,
\end{aligned}
$$

where we have removed the "o" superscript to economize on notation.

\section{IV.B. Analysis without Capacity Constraints}

We start again with the case without the capacity constraints. We will show that even though the time path of resource 
extraction is distorted away from the Hotelling rule, ${ }^{16}$ many qualitative features of equilibrium are shaped by the same forces as in the competitive environment, in particular, by whether the elasticity of demand is greater than or less than 1 , which determines whether incentives to declare war increase or decrease over time. We also show that country $S$ may avoid wars in some of the cases when wars are unavoidable under competitive markets. Nevertheless, a naive conjecture that the monopolistic environment will necessarily reduce the likelihood of war and will make country $S$ better off because it is now acting as a Stackelberg leader and making take-it-or-leave-it offers is not correct. In fact, as we will see, it is possible for war to occur in a monopolistic equilibrium in cases when war can be avoided under competitive markets, and country $S$ can have lower utility. Both of these features are the consequence of a new source of distortion in the monopolistic environment, resulting from the fact that country $S$ cannot commit to making attractive price-quantity offers to country $A$; this, in turn, induces country $A$ to invest in armaments at each date to improve its terms of trade.

We first consider the optimal strategy for country $S$ for a given level of armament $m_{t}$. Let $\tilde{U}_{S}\left(e_{t} ; m_{t}\right)$ be the value function of country $S$ when its makes the best offer that country $A$ accepts, starting with endowment $e_{t}$ and armament level of country $A$ equal to $m_{t}$. This value function is given by the following recursive equation:

$$
\tilde{U}_{S}\left(e_{t} ; m_{t}\right)=\max _{x_{t} \geq 0, c_{t}}\left\{-c_{t}+\beta U_{S}\left(e_{t+1}\right)\right\}
$$

subject to the resource constraint (3), and the participation constraint of country $A$, given by

$$
u\left(x_{t}\right)+c_{t}-l\left(m_{t}\right)+\beta U_{A}\left(e_{t+1}\right) \geq V\left(w\left(m_{t}\right) e_{t}\right)-l\left(m_{t}\right) .
$$

Constraint (21) requires the value of country $A$ when it accepts the price-quantity offer $\left(x_{t}, c_{t}\right)$ at time $t$ to be greater than its utility if it declares war and captures a fraction $w\left(m_{t}\right)$ of the remaining endowment of country $S$. This value also needs to be greater than the continuation value from rejecting the pricequantity offer but not declaring war. But it can be easily verified

16. The key reason for distortions in the monopolistic equilibrium is the armament decision of country $A$. To highlight how armament affects the distortion, in the Online Appendix we also show that when country $A$ can attack country $S$ without arming, wars never occur and the path of resource extraction satisfies the Hotelling rule (16). 
that this latter option is never attractive for country $A$, and hence there is no need to specify it as an additional constraint in the maximization problem (20). ${ }^{17}$

Moreover, it is straightforward to see that constraint (21) must bind in equilibrium, because otherwise country $S$ could make an offer with slightly greater transfers and would increase its payoff. Finally, if $\tilde{U}_{S}\left(e_{t} ; m_{t}\right)$ is less than the payoff from war $\psi$, the best response for country $S$ is to make any offer that violates (21). Thus in equilibrium, starting from $\left(e_{t}, m_{t}\right)$, the payoff of country $A$ is equal to

$$
V\left(w\left(m_{t}\right) e_{t}\right)-l\left(m_{t}\right)
$$

regardless of whether it accepts the price-quantity offer of country $S$. This implies that country $A$ 's best response is to always choose a level of armament maximizing (22). We defined this level of armaments as $m^{*}\left(e_{t}\right)$ in equation (8). Therefore, the equilibrium payoffs for countries $A$ and $S$ can be written as:

$$
U_{A}\left(e_{t}\right)=V\left(w\left(m^{*}\left(e_{t}\right)\right) e_{t}\right)-l\left(m^{*}\left(e_{t}\right)\right)
$$

and

$$
U_{S}\left(e_{t}\right)=\max \left\{\tilde{U}_{S}\left(e_{t} ; m^{*}\left(e_{t}\right)\right) ; \psi\right\} .
$$

We next show that an MPME exists.

LEMMA 3. An MPME exists.

Proof. See the Online Appendix.

We now turn to the first main result of this section.

Proposition 6. In any MPME, if $f_{t+1}=0$, then

$$
\begin{aligned}
& \beta u^{\prime}\left(x_{t+1}\right)>u^{\prime}\left(x_{t}\right) \text { if } m^{* \prime}\left(e_{t+1}\right)>0, \text { and } \\
& \beta u^{\prime}\left(x_{t+1}\right)<u^{\prime}\left(x_{t}\right) \text { if } m^{* \prime}\left(e_{t+1}\right)<0 .
\end{aligned}
$$

Proof. See the Online Appendix.

17. In particular, this additional constraint can be written as $u\left(x_{t}\right)+c_{t}-l\left(m_{t}\right)+$ $\beta U_{A}\left(e_{t+1}\right) \geq u(0)-l\left(m_{t}\right)+\beta U_{A}\left(e_{t}\right)$.Suppose, to obtain a contradiction, that this constraint binds. By definition, $U_{A}\left(e_{t}\right)=u\left(x_{t}\right)+c_{t}-l\left(m_{t}\right)+\beta U_{A}\left(e_{t+1}\right)$, which combined with this (binding) constraint implies that $U_{A}\left(e_{t}\right)=\frac{\left(u(0)-l\left(m_{t}\right)\right)}{(1-\beta)}$, which is necessarily less than $V\left(w\left(m_{t}\right) e_{t}\right)-l\left(m_{t}\right)$, showing that (21) is violated. 
The main technical difficulty in the proof of this proposition lies in the fact that the value function $U_{S}\left(e_{t}\right)$ may not be differentiable; we thus use perturbation arguments in the Online Appendix to prove this result. It is easy to verify this result heuristically if one assumes differentiability. To do this, let us substitute (23) into (20), taking into account that because $f_{t+1}=0$, it is the case that $\tilde{U}_{S}\left(e_{t} ; m_{t}\right)=U_{S}\left(e_{t}\right)$. Take the first-order conditions to obtain

$$
u^{\prime}\left(x_{t}\right)-\beta u^{\prime}\left(x_{t+1}\right)+\beta l^{\prime}\left(m^{*}\left(e_{t+1}\right)\right) m^{* \prime}\left(e_{t+1}\right)=0 .
$$

Since $l^{\prime}(\cdot)>0$, equation (26) implies (25).

Proposition 6 shows that the key determinant of the growth rate of the shadow price of the resource is whether country $A$ increases or decreases armaments as the resource stock declines. This result is driven by the inabilities of both countries to commit to future actions. If country $S$ could commit in period 0 to a sequence of offers $\left\{z_{t}\right\}_{t=0}^{\infty}$, only a one-time investment in armament by country $A$ would be necessary and this would prevent war; the shadow price of the resource would also grow at the rate of time preference, $\frac{(1-\beta)}{\beta}$, as in the Hotelling rule. In our model, such commitment is not possible. Country $A$ needs to invest in armament in each period to obtain better terms of trade from country $S$. In particular, given the timing of events, it is clear that country $A$ will choose armaments at each date to maximize its continuation value $V\left(w\left(m_{t}\right) e_{t}\right)-l\left(m_{t}\right)$, because this will be its utility given country $S$ 's take-it-or-leave-it offer. This continuation value incorporates the sequence of future armament costs as well, and so country $S$ will take these into account also when deciding path of extraction and prices. To develop this intuition further, let us substitute (23) into (21):

$$
\begin{gathered}
u\left(x_{t}\right)+c_{t}+\beta\left(V\left(w\left(m^{*}\left(e_{t+1}\right)\right) e_{t+1}\right)-l\left(m^{*}\left(e_{t+1}\right)\right)\right) \\
\geq V\left(w\left(m^{*}\left(e_{t}\right)\right) e_{t}\right) .
\end{gathered}
$$

Suppose that armaments increase as the resource stock decreases. The increase in $m_{t}$ implies that constraint (28) becomes harder to satisfy over time. If country $S$ extracts $\epsilon$ units of resources less in period $t$ and $\epsilon$ more in period $t+1$, holding everything fixed, it changes the payoff to country $A$ by $\left(\beta u^{\prime}\left(x_{t+1}\right)-u^{\prime}\left(x_{t}\right)\right) \epsilon$. In addition, it relaxes constraint (28) since the stock of resources is higher so that armament by country $A$ declines, and this allows country $S$ to decrease the offer of $c_{t}$. Therefore, as long as $\beta u^{\prime}\left(x_{t+1}\right)-u^{\prime}\left(x_{t}\right) \geq 0$, country $S$ can be made better off by 
postponing resource extraction to next period. Thus, it must be the case that $\beta u^{\prime}\left(x_{t+1}\right)-u^{\prime}\left(x_{t}\right)<0$ in equilibrium. When the amount of armament is decreasing in $e_{t}$, this effect works in the opposite direction.

Proposition 1 showed that the sign of $m^{* \prime}(e)$ is determined by elasticity of demand for the resource. Using Proposition 1 we next obtain the following corollary to Proposition 6, linking the direction of deviations from the Hotelling rule to the elasticity of demand for the resource.

COROLLARY 2. In any MPME, whenever $f_{t+1}=0$, we have that

$$
\text { if }-u^{\prime}(x) /\left(x u^{\prime \prime}(x)\right)>(<) 1 \text { for all } x \text {, then } \beta u^{\prime}\left(x_{t+1}\right)>(<) u^{\prime}\left(x_{t}\right) \text {. }
$$

We saw in Section III that the elasticity of demand played a crucial role in determining whether incentives to declare war increase or decrease as the endowment of the resource is depleted. The same effect determines the equilibrium armaments for country $A$ in the monopolistic environment. When demand is inelastic, the value of the resource, $V^{\prime}\left(e_{t}\right) e_{t}$, increases over time. This induces country $A$ to invest more in armaments. Country $S$ internalizes the effect of resource depletion on country $A$ 's incentives to arm (as it can hold country $A$ down to its continuation value). It then counteracts the rise in country $A$ 's armament costs by reducing the rate of resource extraction. This is equivalent to a (shadow) price sequence growing at a slower rate than the rate of time preference, $\frac{(1-\beta)}{\beta}$. In contrast, when demand is elastic, the value of the resource and country $A$ 's armaments are decreasing over time. In this case, country $S$ can further reduce country $A$ 's armament costs by raising the rate of resource depletion.

We now turn to the analysis of the conditions under which peace occurs in the monopolistic environment. A naive conjecture is that country $S$ 's ability to regulate the price and the level of production of the resource makes wars less likely and its citizens better off relative to the competitive equilibrium. This conjecture is not correct, however, because of the commitment problem, which leads to a new distortion in this monopolistic environment. Recall that at each date country $S$ makes a price-quantity offer that gives to country $A$ utility equal to $V\left(w\left(m_{t}\right) e_{t}\right)-l\left(m_{t}\right)$. It cannot commit to giving a higher utility to country $A$, unless the latter invests more in armaments. So country $A$ needs to invest in armaments at each date to secure favorable terms of trades. Therefore, the monopolistic environment encourages investments 
in armaments at each date, whereas in the competitive environment country $A$ did not need to invest in arms in periods in which it did not declare war. Moreover, since country $S$ needs to give country $A$ at least utility $U_{A}\left(e_{t}\right)=V\left(w\left(m^{*}\left(e_{t}\right)\right) e_{t}\right)-l\left(m^{*}\left(e_{t}\right)\right)$, it effectively pays for country $A$ 's future costs of armaments, so country $S$ may be made worse off by its ability to make take-it-orleave-it offers or by its inability to commit to future paths of prices and production. The next proposition exploits this new distortion and shows why the above-mentioned conjecture is incorrect.

Proposition 7. Suppose $u(x)$ satisfies (17). Then in any MPME,

1. War is avoided when $\sigma<1$ and

$$
-\beta l(\bar{m})>\psi(1-\beta) .
$$

2. War can be avoided when war necessarily occurs in an MPCE.

3. War occurs with probability 1 along the equilibrium path if $\sigma<1$ and

$$
\begin{aligned}
& -\beta l\left(m^{*}\left(e_{0}\right)\right)<\psi(1-\beta) \\
& \quad-\left(V\left(e_{0}\right)-V\left(w\left(m^{*}\left(e_{0}\right)\right) e_{0}\right)\right)(1-\beta) .
\end{aligned}
$$

4. War can occur with probability 1 along the equilibrium path when war is necessarily avoided in the MPCE.

Proof. See the Online Appendix.

The first part of the proposition shows that under some circumstances, the ability for country $S$ to control resource extraction allows it to avoid wars in situations in which the cost of armament is bounded below by the cost of war. For instance if $\psi=-\infty$, so that war is infinitely costly to country $S$, then country $S$ avoids war in any monopolistic equilibrium and this is true even though wars may be inevitable in the competitive equilibrium. Similarly, if $\bar{m}<\infty$, war does not take place in MPME for large but finite $\psi$. The second part of the proposition is a simple consequence of the first. When war is highly costly to country $S$, it still takes place in the competitive environment, but not in the monopolistic environment under the conditions identified in part 1 of the proposition (for example, war never takes place in MPME when $\psi=-\infty)$. Note that in this case, country $S$ 's utility will clearly be higher in the monopolistic environment. 
Nonetheless, parts 3 and 4 of the proposition show that the opposite of these conclusions might also be true. In particular, if $\psi$ is sufficiently low, offers necessary to secure peace may be very costly for country $S$, especially because it is implicitly paying for the costs of future armament. In this case, wars can occur along the equilibrium path. More specifically, in contrast to Section III, country $A$ needs to make costly investments in armament in each period, even if war does not take place. This is because, as noted, country $S$ cannot commit to making attractive offers unless country $A$ has an effective threat of war, and thus country $A$ is induced to invest in armament to improve its terms of trade. But this means that war will reduce future costs of armament; consequently, to secure peace, country $S$ must make offers that compensate country $A$ for the costs of future armament. If these costs are increasing to infinity along the equilibrium path, then the cost to country $S$ of such offers will eventually exceed the cost from war, $-\psi$, which means that war cannot be permanently avoided. More generally, this cost of war may be sufficiently low that country $S$ prefers to allow immediate war in the monopolistic equilibrium even though war does not occur in the competitive equilibrium. ${ }^{18}$

In sum, allowing country $S$ to control the extraction of resources introduces two new economic forces relative to the competitive environment. First, it implies that country $S$ controls the externalities generated by competitive firms. Second, it also introduces a new strategic interaction between the two countries because country $S$ can control the terms of trade directly but is unable to commit to making these terms sufficiently attractive for country $A$ without armaments. This lack of commitment implies that country $A$ will have an incentive to use investments in armaments to enhance its terms of trade. The first force implies that war can be avoided in the monopolistic equilibrium in situations

18. Though, as we have emphasized, the commitment problem facing country $S$ is essential for the result that inefficient war can happen in MPME, commitment by country $A$ to limit its armaments in the future (say, to be no more than some small $\epsilon>0$ ) could also prevent war and may lead to a Pareto superior allocation. For example, a commitment by country $A$ that in the future it will only have no or little armament implies that country $S$ will have a high payoff from tomorrow onward and country $A$ will have a low payoff. If country $A$ chooses high armaments today, this would force country $S$ to make a large transfer today, and from tomorrow onward, resources would be traded at undistorted market prices without war. This discussion highlights that lack of commitment on the part of both countries is important for the presence of inefficient war. 
in which it is inevitable in the competitive equilibrium. The second force implies that since country $A$ must now invest in armament under peace, war takes place in the monopolistic equilibrium even when it can be avoided in the competitive equilibrium.

\section{IV.C. Analysis with Capacity Constraints}

It is straightforward to show that the characterization in Proposition 6 continues to apply in an environment with capacity constraint $\bar{x}$, and implies that if $x_{t}<\bar{x}$ and $x_{t+1}<\bar{x}$, then the deviation from the Hotelling rule at time $t$ depends on the sign of $m^{* \prime}\left(e_{t+1}\right)$ :

Proposition 8. In any MPME, if $f_{t+1}=0, x_{t}<\bar{x}$, and $x_{t+1}<\bar{x}$, then

$$
\begin{aligned}
& \beta u^{\prime}\left(x_{t+1}\right)>u^{\prime}\left(x_{t}\right) \text { if } m^{* \prime}\left(e_{t+1}\right)>0, \text { and } \\
& \beta u^{\prime}\left(x_{t+1}\right)<u^{\prime}\left(x_{t}\right) \text { if } m^{* \prime}\left(e_{t+1}\right)<0 .
\end{aligned}
$$

Proof. See the Online Appendix.

The intuition for why deviations from the Hotelling rule emerge and depend on the sign of $m^{* \prime}\left(e_{t+1}\right)$ is the same as in the case without capacity constraints. Moreover, Corollary 2 also continues to apply and implies that deviations from the Hotelling rule depend on the elasticity of demand.

The analysis is more complicated when either $x_{t}$ or $x_{t+1}$ is at capacity. The next proposition provides a partial characterization for the case in which there is no war along the equilibrium path.

Proposition 9. Suppose that in an MPME, $f_{t}=0$ for all $t \geq 0$. Then:

1. If $\frac{-u^{\prime}(x)}{\left(x u^{\prime \prime}(x)\right)}>1$ for all $x$, then there exists a $T \geq 0$ such that $x_{t}=\bar{x}$ for all $t \leq T$ and $\beta u^{\prime}\left(x_{t+1}\right)>u^{\prime}\left(x_{t}\right)$ for all $t>T$.

2. If $\frac{-u^{\prime}(x)}{\left(x u^{\prime \prime}(x)\right)}<1$ for all $x$, then $x_{t}<\bar{x}$ and $\beta u^{\prime}\left(x_{t+1}\right)<u^{\prime}\left(x_{t}\right)$ for all $t$.

Proof. See the Online Appendix.

If preferences are elastic, then $m^{* \prime}\left(e_{t+1}\right)>0$ and country $S$ wishes to extract resources faster than under the Hotelling rule to speed up disarmament by country $A$. As a consequence, the capacity constraint may bind for a number of periods initially, and thereafter, the first-order condition (26) will hold and the result will again be that $\beta u^{\prime}\left(x_{t+1}\right)>u^{\prime}\left(x_{t}\right)$. If preferences are 
inelastic, then country $S$ wishes to extract resources more slowly than under the Hotelling rule as $m^{* \prime}\left(e_{t+1}\right)<0$, and this will slow down resource extraction. In this case, the capacity constraints never bind because by Assumption 1.3, they do not bind under the Hotelling rule. As a result, (26) again holds and $\beta u^{\prime}\left(x_{t+1}\right)<u^{\prime}\left(x_{t}\right)$.

\section{CASe Studies}

In this section, we briefly discuss two case studies that illustrate the insights generated by our theory, in particular, highlighting the potential roles of scarcity, demand elasticity, and regulation of prices and quantities in the initiation of resource wars. ${ }^{19}$

\section{V.A. War of the Pacific}

The War of the Pacific (Guerra del Pacífico) was fought between 1879 and 1884 by Chile against Bolivia and Peru. It is commonly argued that the primary cause for the conflict were the deposits of nitrates, guano (bird excrement), and saltpeter (see e.g., Dennis 1927; Farcau 2000). Farcau (2000) describes the history of the guano deposits in Atacama Desert. Guano had a limited use as fertilizer by the Incas and Spanish colonists prior to nineteenth century. After the demonstration of the viability of extraction of significant quantities of nitrates and their importance for plant growth in 1840 , this resource became highly valuable. An additional important use of the nitrates was as an ingredient in explosives. Dennis $(1927,27)$ writes, "All the wealth of Pizzaro and Cortes and their followers is a small item compared to what this desert has yielded. Counting both the guano and the nitrates ... the wealth ... exceeded all the gold and silver of the Andes. This was the prize of war."

Bakeless (1921) concludes:

The economic character of this war is self evident. The boundary question between Chile and Bolivia had existed for a long time without ever having been seriously considered, much less leading to any signs of hostilities. It was only when the valuable mineral

19. For a comprehensive set of case studies on war and environment, see the Trade and Environment Database and Inventory of Conflict and Environment at the American University in Washington, D.C. Our discussion here partially draws on the information description in these databases. 
deposits were found that the states became sufficiently concerned about their boundaries..., and the rivalry of Peruvian guano and Chilean nitrate fanned the flames. ... it was the possession of Tacna, Arica, and Tarapaca, with their nitrate deposits, upon which the victors were intent.

Sicotte, Vizcarra, and Wandschneider (2009) provide detailed evidence on the value of the deposits, and argue that they were the world's only commercially viable deposits of sodium nitrate before World War I. The value of the reserves appears to have been comparable to the current value of oil reserves in the Gulf. For example, nitrate revenues constituted at least $20 \%$ of all Peruvian government revenues before 1879 . The income from the nitrates for the victorious Chile rose to $48 \%$ of the government revenues and remained at about that level until the World War I. Crow $(1992,647)$ documents that Chilean national revenue increased from 15 million pesos to 60 million pesos between 1880 and 1890 .

There is also evidence that demand for the nitrates was inelastic. Matthew (1970, 124-25) argues that in Britain (one of the key importers) the demand elasticity for nitrates was low; despite higher prices, British farmers did not want to substitute to other fertilizers.

In line with insights of our theory, monopolization of the extraction of guano was attempted to stall the war, and it appears that the failure of this attempt was an important factor in the onset of the war. A boundary treaty of 1866 between Chile and Bolivia established that the current and future revenues would be shared with Chile. Article 2 of the treaty states that "Bolivia and Chile shall share equally the proceeds of exploitation of the guano deposits discovered ... or which may be discovered." Article 3 establishes that only one custom house would collect all the proceeds. The Protocol of 1872 (Lindsay-Corral Agreement) further developed the treaty with respect to monopolization of the industry: "Article $4 \ldots$ Chile and Bolivia will adopt a common system of regulation in order to derive most possible from the industry." ${ }^{20}$ Dennis (1927, 27-28) writes: "Huge nitrate interests also soon became an object of rivalry. If the great banking groups of Europe, Valparaiso, and Lima had agreed on an economic policy there would have been no war, for the government of Chile had 
to be dragged into war, while Bolivia and Peru were completely unprepared.... The above statement of the cause of the war seems at first extreme, but is well substantiated."

There is also evidence that the increasing price of guano before the war related to increased military expenditures. Between 1852 and 1858, for example, Peruvian military spending increased fourfold (Vizcarra, 2009, 370).

\section{V.B. Cedar Wars}

Starting from the third millennium B.C., the cedar trees of ancient Lebanon were an important and valuable natural resource and appear to have been the major factor leading to the Cedar Wars in ancient Lebanon (Kasoff, 1997). We closely follow the discussion of Kasoff (1997) and the references therein. Phoenicians used these trees for building ships and the Egyptians used them for the ceremonial purposes. The extensive use and the exploitation of the forests led to their rapid dwindling. As Kasoff (1997) writes, "The scarcity of trees was so noticeable that, over time, the few remaining tall trees even became objects of worship."

The primary cause for the several wars over this period appears to have been cedar. Kasoff(1997) argues this drawing extensively on two prominent studies; Meiggs (1982) is an authoritative study of the trees in ancient Mediterranean and Mikesell (1969) is an extensive account of deforestation of Mount Lebanon. "Cedar was thought to be the prize which all the states of the Near East coveted, and for which the empires of Egypt and Mesopotamia were prepared to fight" (Meiggs 1982, 55). Babylonian King Nebuchadnezzar described the reason for the military campaigns to the logging of the cedars: "I cut through steep mountains, I split rocks, opened passages and [thus] I constructed a straight road for the [transport of the] cedars. I made the Arahtu float [down] and carry to Marduk, my lord, mighty cedars, high and strong, of precious beauty and of excellent dark quality, the abundant yield of Lebanon, as [if they be] reed stalks carried by the river" (Mikesell 1969, 13).

Notably, not just the value of cedar but also its potential future scarcity is cited as an important cause of the wars. Kasoff (1997) writes,

Egyptians and Mesopotamians used military means to overcome a domestic shortage of a natural resource which was slow to replenish itself. Leaders of these 
various nations then, looked at wood as a justification for military campaigns; the exaction of tribute enabled conquerors of the Levant to appropriate, and thence denude, parts of the Levant's rich supply of forested land. By doing this, they easily circumvented shortcomings at home. Spoils of victory in the ancient Near East, then, included wood from Lebanon [sic].

Semple $(1931,271)$ provides evidence that a main objective of the Phoenician invasion of Cyprus in the eleventh century B.C. was scarcity of the trees and an attempt to conserve the timber from the mountains of Lebanon. Cedar was essentially an exhaustible, nonrenewable resource because supply was limited to the eastern Mediterranean and new trees took a very long time to grow (Semple 1931). The evidence also suggests that the demand for cedar was inelastic. For example, Baramki (1961) writes:

From the location of Phoenician settlement, it may be extrapolated that the cedar timber from Lebanon, by virtue of its geographical proximity, provided an integral-perhaps even a necessary-resource with which their thalassocracy [maritime empire] was established and on which it thrived... Phoenicia, especially Byblos, supplied Egypt with the timber which she needed for her buildings, her boats, her furniture and fuel, and especially her funerary equipment. Vast quantities of cedar and pine timber were made into rafts and towed by boats from Byblos, mainly to Egypt, as early as 2800 B.C. (63)

Another important fact that relates to our model is how wars were used to affect the terms of trade. During the military campaigns of 734 and 733-732 B.C., Assyrian King TiglathPileser III, who controlled Phoenicia, imposed a trade embargo on the export of timber from Lebanon to Egypt. For Egypt, as we argued, cedar was an essential commodity, used in building temples and funeral ceremonies. A trade embargo by the Assyrians was very costly for the Egyptians, as the tall cedar trees were impossible to substitute. Egyptians, therefore, attempted to support rebellions in Palestine against the Assyrians (see, e.g., Nemet-Nejat 1989, 38). We interpret these actions by the Egyptians as an attempt to change the terms of trade-to 
overthrow the Assyrians to ensure that the embargo is repealed and the trade with Egypt would be resumed.

\section{EXTENSIONS}

In this section, we discuss several extensions that show both the robustness of the insights discussed so far and indicate new interesting effects. To simplify the discussion, we consider the environment with no capacity constraints, that is, $\bar{x}=\infty$. Also to simplify the exposition in this section we impose that $\psi=-\infty$ so that wars never occur in an MPME. The Online Appendix presents two additional extensions: first, an environment with multiple resource-rich countries as well as multiple resourcepoor countries, and second, an environment with more general preferences.

\section{VI.A. Intercountry Competition}

In this subsection we consider the implications of allowing for $N$ resource-poor countries, denoted by $i=1, \ldots, N$, to compete over the resources from country $S$. The economy is identical to that of Section IV, though the resource constraint is replaced by

$$
e_{t+1}=e_{t}-\sum_{i=1}^{N} x_{i t},
$$

where $x_{i t} \geq 0$ corresponds to the consumption of the resource by the households (each of mass 1 ) in country $i$ and $c_{i t} \gtreqless 0$ again refers to the consumption good. The instantaneous utility to country $i$ from its consumption of the resource and the consumption good is equal to $u\left(x_{i t}\right)+c_{i t}$ and it discounts the future at the rate $\beta$. As such, country $S$ 's instantaneous utility from the consumption good equals $\sum_{i=1}^{N}-c_{i t}$ and it discounts the future at the rate $\beta$.

At any date $t$, country $i$ can invest in armament $m_{i t} \geq 0$ at cost $l\left(m_{i t}\right)$ and declare war. We assume that if any country declares war, all countries join the war, so that we have a "world war." In such a war, the fraction of the remaining endowment of resources captured by country $i$ is assumed to be

$$
w_{i}\left(m_{i t}, \mathbf{m}_{-i t}\right)=\eta \frac{h\left(m_{i t}\right)}{\sum_{j=1}^{N} h\left(m_{j t}\right)},
$$

where $\mathbf{m}_{-i t}=\left\{m_{j t}\right\}_{j=1, j \neq i}^{N}$ is the vector of armaments by other countries, $\eta \in(0,1]$, and $h$ is increasing, continuously differentiable, 
and concave. These assumptions imply that total amount of resources after the war is possibly less than the endowment before the war (and thus the interpretation is that each of the $N$ resource-poor countries invades part of the territory of country $S)$. Naturally, $w_{i}\left(m_{i t}, \mathbf{m}_{-i t}\right)$ is increasing in own armament and decreasing in the armament of other countries. This specification is particularly tractable because it implies that the continuation value to country $i$ from war is equal to $V\left(w_{i}\left(m_{i t}, \mathbf{m}_{-i t}\right) e_{t}\right)-l\left(m_{i t}\right)$ for $V(\cdot)$ defined as in (4). Given this modified environment, $f_{T}=0$ now denotes that no war has been declared by any country in periods $t=0, \ldots, T$, and we let $f_{T}=1$ denote that war has been declared by some country in period $t \leq T .^{21}$

First note that the MPCE in this extended environment with multiple resource-poor countries is similar to Proposition 2. In particular, in the pure-strategy equilibrium, war can only take place at date $t=0$ and the Hotelling rule applies throughout. In what follows, we focus on MPME.

At every date $t$, country $S$ 's government publicly makes a take-it-or-leave-it offer to each country $i,\left\{x_{i t}^{o}, c_{i t}^{0}\right\}$, consisting of a quantity of resource to be traded in exchange for the consumption good for each $i$. For simplicity, we assume that rejection of the offer by any country $i$ automatically leads to world war. follows:

The order of events for all periods $t$ for which $f_{t-1}=0$ is as

1. Each country $i$ government chooses a level of armament $m_{i t}$.

2. Country $S$ 's government makes a take-it-or-leave-it offer $\left\{x_{i t}^{o}, c_{i t}^{0}\right\}$ to each $i$.

3. Each country $i$ government decides whether to declare world war.

4. Extraction and consumption take place.

Using this framework, we can define the MPME as in Section IV. We define $U_{i}\left(e_{t}\right)$ as the continuation value to country $i$ conditional on $e_{t}$ and $f_{t-1}=0$ and we define $U_{S}\left(e_{t}\right)$ analogously for country $S$. Since $\psi=-\infty$, war is always avoided along the equilibrium path.

By the same reasoning as in Section IV, country $i$ chooses the level of armament at each date to maximize its payoff from war to

21. Our analysis can also be interpreted as applying to a situation in which only country $i$ attacks country $S$ and it seizes a fraction of the resource which is decreasing in the armament of its rivals. 
receive the most favorable offer from country $S$. More specifically, it must be that in equilibrium $m_{i t}=\widetilde{m}_{i}^{*}\left(e_{t}, \mathbf{m}_{-i t}\right)$ for

$$
\tilde{m}_{i}^{*}\left(e_{t}, \mathbf{m}_{-i t}\right)=\arg \max _{m_{i} \geq 0} V\left(w_{i}\left(m_{i}, \mathbf{m}_{-i t}\right) e_{t}\right)-l\left(m_{i}\right),
$$

which is uniquely defined, satisfies $\widetilde{m}_{i}^{*}\left(e_{t}, \mathbf{m}_{-i t}\right)>0$, and is a continuously differentiable function in all of its elements. This implies an analogous equation to (23):

$$
U_{i}\left(e_{t}\right)=V\left(w_{i}\left(\widetilde{m}_{i}^{*}\left(e_{t}, \mathbf{m}_{-i t}\right), \mathbf{m}_{-i t}\right) e_{t}\right)-l\left(\tilde{m}_{i}^{*}\left(e_{t}, \mathbf{m}_{-i t}\right)\right)
$$

for all $i$ where $m_{j t}=\tilde{m}_{j}^{*}\left(e_{t}, \mathbf{m}_{-j t}\right)$ for all $j$. Note that given this formulation, $U_{i}\left(e_{t}\right)$ may not necessarily be continuously differentiable in each MPME, as it was in the case of Section IV. To simplify the discussion, let us also focus on symmetric MPME, where $m_{i}^{*}\left(e_{t}\right)=m^{*}\left(e_{t}\right)$ for all $i$ and country $S$ make the same offer to each $i$ in each date. A symmetric MPME always exists and in such an equilibrium $U_{i}\left(e_{t}\right)$ is differentiable (from a straightforward application of the implicit function theorem). Since in a symmetric equilibrium all countries choose the same armament $m^{*}\left(e_{t}\right)$, we have that $w_{i}\left(m_{i t}, \mathbf{m}_{-i t}\right)=\frac{\eta}{N}$ for each $i$.

Proposition 10. In any symmetric MPME,

1. For country $i$, resource extraction satisfies

$$
\begin{aligned}
& \beta u^{\prime}\left(x_{i t+1}\right)>u^{\prime}\left(x_{i t}\right) \text { if } m_{i}^{* \prime}\left(e_{t+1}\right)>0 \text { and } \\
& \beta u^{\prime}\left(x_{i t+1}\right)<u^{\prime}\left(x_{i t}\right) \text { if } m_{i}^{* \prime}\left(e_{t+1}\right)<0 .
\end{aligned}
$$

2. If $u$ satisfies

$$
\frac{-u^{\prime}(x)}{\left(x u^{\prime \prime}(x)\right)}>(<) 1 \text { for all } x,
$$

then $m_{i}^{* \prime}\left(e_{t}\right)>(<) 0$ for all $i$.

Proof. See the Online Appendix.

Proposition 10 states that the shadow value of resources in country $i$ grows faster or slower than the rate of time preference, $\frac{(1-\beta)}{\beta}$, depending on whether the level of armament is rising or decreasing in the resource endowment. It is important to note that the argument leading to this result relates to how armament for all countries moves as the endowment declines. Thus the intuition for Proposition 10 is similar to that of Proposition 6 except that we 
must now take into account how future values of the endowment $e_{t+1}$ affect the armament of all countries jointly.

It is also noteworthy that in a symmetric equilibrium, by definition, armament decisions of different countries will co-move as the endowment depletes. The second part of Proposition 10, which is similar to Proposition 1, states that whether armament increases or decreases as the endowment is depleted depends on the elasticity of demand. This co-movement incorporates the best responses of each resource-poor country to the armaments decisions of its neighbors.

To illustrate the complementarity in armament decisions across countries and its implications, consider a simple example in which we can explore the consequences of changing the number of competing countries $N$. Suppose that preferences satisfy (17) so that the elasticity of demand is constant. Moreover, let $w_{i}(\cdot)$ and $l(\cdot)$ take the following functional forms:

$$
w_{i}\left(m_{i t}, \mathbf{m}_{-i t}\right)=\frac{m_{i t}}{\sum_{j=1}^{N} m_{j t}} \text { and } l\left(m_{i t}\right)=m_{i t} .
$$

In this environment, it can be shown that the symmetric MPME is unique and involves:

$$
m_{i}^{*}\left(e_{t}\right)=\left(\frac{N-1}{N}\right)\left(1-\beta^{\sigma}\right)^{-\frac{1}{\sigma}}\left(\frac{e_{t}}{N}\right)^{1-\frac{1}{\sigma}} .
$$

This means that conditional on per-country endowment level $\frac{e_{t}}{N}$, the level of armament is increasing in military competition parameterized by $\frac{(N-1)}{N}$. Intuitively, if there are more resourcepoor countries competing for the same total endowment, returns to arming will be higher and these returns will become more sensitive to changes in the per-country endowment. Naturally, country $S$ takes this into account in deciding the time path of extraction. This reasoning establishes the following proposition.

Proposition 11. Suppose that preferences and technologies satisfy (17) and (33). Then in the symmetric MPME:

1. There exists $\rho>0$ such that $u^{\prime}\left(x_{i t+1}\right)=\left(\frac{1}{\rho}\right) u^{\prime}\left(x_{i t}\right)$ for all $t$.

2. $\frac{1}{\rho}>(<) \frac{1}{\beta}$ if $\sigma>(<) 1$.

3. $|\rho-\beta|$ is increasing in $N$ if $\sigma \neq 1$.

Proof. See the Online Appendix. 
This proposition states that under (17) and (33) the growth rate of the shadow value of the resource is constant and depends on the elasticity of substitution $\sigma$. Interestingly, the last part of the proposition states that the distortion in this growth rate from the Hotelling rule is increasing in the level of international competition. The intuition for this is that as (34) shows, when $N$ is greater, the marginal benefit of armament is also greater, implying that global armament becomes more sensitive to changes in the resource endowment. For instance, if $\sigma<1$ so that armament is increasing along the equilibrium path, an increase in the level of international competition (captured by a higher $N$ ) raises global armaments (because of the complementarities in armament decisions) and induces country $S$ to further slow down resource extraction so as to mitigate the rise in armament coming from all $N$ countries (for which it is paying indirectly through lower prices).

\section{VI.B. Armament in Defense}

In practice, a defending country $S$ can also invest in armament to deter an attack. In this subsection, we extend the baseline environment to allow for armaments by country $S$. We focus on MPME. ${ }^{22}$ More specifically, at each $t$, country $S$ can invest in armament $m_{S t} \geq 0$, which costs $l\left(m_{S t}\right)$ whereas country $A$ invests in armament $m_{A t} \geq 0$, which costs $l\left(m_{A t}\right)$ as before. Country $S$ still receives payoff $\psi$ in the event of war, though country $A$ 's payoff now depends on both countries' armaments. In particular, it receives a fraction of the remaining endowment $w\left(m_{A t}, m_{S t}\right)$. We assume that $w(\cdot, \cdot)$ satisfies

$$
w\left(m_{A t}, m_{S t}\right)=\eta \frac{h\left(m_{A t}\right)}{h\left(m_{A t}\right)+h\left(m_{S t}\right)},
$$

where $\eta \in(0,1]$ and $h$ is increasing, continuously differentiable and concave.

The order of events at $t$ if $f_{t-1}=0$ is the same as in Section IV, with the exception that in the first stage, countries $A$ and $S$ simultaneously choose $m_{A t}$ and $m_{S t}$. Using this framework, we can define the MPME as in Section IV with $U_{A}\left(e_{t}\right)$ and $U_{S}\left(e_{t}\right)$

22. The analysis of MPCE is more involved in this case, though it can again be shown that given our assumptions here, war must take place at date $t=0$ (if it will take place at all). 
denoting the continuation values to countries $A$ and $S$, respectively, given endowment $e_{t}$.

By the same reasoning as before, at each $t$ country $A$ chooses the level of armament that maximizes its payoff from war receive the most favorable offer from country $S$. More specifically, it must be that in equilibrium $m_{A t}=\widetilde{m}_{A}^{*}\left(e_{t}, m_{S t}\right)$ for

$$
\widetilde{m}_{A}^{*}\left(e_{t}, m_{S t}\right)=\arg \max _{m_{A} \geq 0} V\left(w\left(m_{A}, m_{S t}\right) e_{t}\right)-l\left(m_{A}\right) .
$$

Given our assumptions on $u(\cdot), w(\cdot)$, and $l(\cdot), \tilde{m}_{A}^{*}\left(e_{t}, m_{S t}\right)>0$ and is a continuously differentiable function of its arguments. Because country $S$ 's offers make country $A$ indifferent to war and no war, a similar equation to (23) holds:

$$
U_{A}\left(e_{t}\right)=V\left(w\left(\tilde{m}_{A}^{*}\left(e_{t}, m_{S t}\right), m_{S t}\right) e_{t}\right)-l\left(\tilde{m}_{A}^{*}\left(e_{t}, m_{S t}\right)\right) .
$$

Moreover, analogous arguments to those of Section IV imply that if $\tilde{U}_{S}\left(e_{t} ; m_{A t} ; m_{S t}\right)$ corresponds to country $S$ 's welfare from its optimal offer conditional on $e_{t}, m_{A t}$, and $m_{S t}$, then it must satisfy:

$$
\tilde{U}_{S}\left(e_{t} ; m_{A t} ; m_{S t}\right)=\max _{x_{t} \geq 0, c_{t}}\left\{-c_{t}-l\left(m_{S t}\right)+\beta U_{S}\left(e_{t+1}\right)\right\}
$$

subject to equation (3), and

$$
u\left(x_{t}\right)+c_{t}-l\left(m_{A t}\right)+\beta U_{A}\left(e_{t+1}\right) \geq V\left(w\left(m_{A t}, m_{S t}\right) e_{t}\right)-l\left(m_{A t}\right) .
$$

Because we assumed that $\psi=-\infty$, country $S$ always makes an offer which is accepted and $U_{S}\left(e_{t}\right)=\tilde{U}_{S}\left(e_{t} ; m_{A t}, m_{S t}\right)$. Since constraint (36) will bind in equilibrium, we can substitute (36) into equation (35) and obtain the value of $m_{S t}$ that maximizes $U_{S}\left(e_{t}\right)$ is given by

$$
\tilde{m}_{S}^{*}\left(e_{t}, m_{A t}\right)=\arg \max _{m_{S} \geq 0}-V\left(w\left(m_{A t}, m_{S t}\right) e_{t}\right)-l\left(m_{S}\right) .
$$

Clearly, when strictly positive, $m_{S}^{*}\left(e_{t}, m_{A t}\right)$ is continuously differentiable.

Note that given this formulation, and in contrast to our results in Section IV, $U_{A}\left(e_{t}\right)$ may not be differentiable. To facilitate the exposition in this subsection, we focus on a "differentiable" MPME where it is indeed differentiable. Then, the first-order conditions characterizing $\widetilde{m}_{A}^{*}\left(e_{t}, m_{S t}\right)$ and $\widetilde{m}_{S}^{*}\left(e_{t}, m_{A t}\right)$ are given by

$$
V^{\prime}\left(w(\cdot) e_{t}\right) e_{t} \eta \frac{h^{\prime}\left(m_{A t}\right) h\left(m_{S t}\right)}{\left(h\left(m_{A t}\right)+h\left(m_{S t}\right)\right)^{2}}=l^{\prime}\left(m_{A t}\right), \text { and }
$$




$$
V^{\prime}\left(w(\cdot) e_{t}\right) e_{t} \eta \frac{h^{\prime}\left(m_{S t}\right) h\left(m_{A t}\right)}{\left(h\left(m_{A t}\right)+h\left(m_{S t}\right)\right)^{2}}=l^{\prime}\left(m_{S t}\right) .
$$

The convexity of the $l$ function and the concavity of the $h$ function imply that $\widetilde{m}_{A}^{*}\left(e_{t}, m_{S t}\right)=\widetilde{m}_{S}^{*}\left(e_{t}, m_{A t}\right)$, so that $w(\cdot)$ is always constant and equal to $\frac{\eta}{2} .{ }^{23}$ This means that in this environment one can define $\left\{m_{A}^{*}\left(e_{t}\right), m_{S}^{*}\left(e_{t}\right)\right\}$, which represents two continuously differentiable functions corresponding to the equilibrium levels of armament for each country conditional on the endowment $e_{t}$.

Proposition 12. In any differentiable MPME, we have that:

1. Resource extraction satisfies

$$
\begin{aligned}
& \beta u^{\prime}\left(x_{t+1}\right)>u^{\prime}\left(x_{t}\right) \text { if } m_{i}^{* \prime}\left(e_{t+1}\right)>0 \text { for } i \in\{A, S\}, \text { and } \\
& \beta u^{\prime}\left(x_{t+1}\right)<u^{\prime}\left(x_{t}\right) \text { if } m_{i}^{* \prime}\left(e_{t+1}\right)<0 \text { for } i \in\{A, S\} .
\end{aligned}
$$

2. If $u$ satisfies

$$
\frac{-u^{\prime}(x)}{\left(x u^{\prime \prime}(x)\right)}>(<) 1 \text { for all } x,
$$

then $m_{A}^{* \prime}\left(e_{t}\right)>(<) 0$ and $m_{S}^{* \prime}\left(e_{t}\right)>(<) 0$.

Proof. See the Online Appendix.

Proposition 12 states that the shadow value of the resource rises slower relative to the Hotelling rule if $m_{A}^{*}\left(e_{t+1}\right)$ and $m_{S}^{*}\left(e_{t+1}\right)$ rise as the resource is depleted. The intuition for this result is analogous to that of Proposition 6 except that in addition to considering the future armament of country $A$, country $S$ 's extraction decisions take into account how future values of the endowment will affect its own armament and through this channel also affect country $A$ 's armament (which co-moves with country $S$ 's armament).

The second part of the proposition states that if the elasticity of demand exceeds 1 , then the armaments of both country $A$ and country $S$ decline as the resource is depleted along the equilibrium path. The intuition for this result is the same as that for Proposition 1, with the exception that it takes into account how country $A$ and country $S$ are choosing armaments that optimally react to each other. In particular, when the elasticity of

23. Note that $h(\cdot)$ and $l(\cdot)$ could be scaled by a player specific constant so that $w(\cdot)$ can be equal to a different constant without changing any of our results. 
demand is less than 1 , the same forces as in Proposition 1 push armaments by country $A$ to increase over time. The equilibrium response of country $S$ then leads to increasing armaments by both countries.

\section{VI.C. Further Extensions and Discussion}

In this subsection, we discuss several alternative approaches one could adopt within the broad umbrella of the framework developed in this article. A full analysis of these extensions is beyond the scope of the current article, though we believe this framework can be fruitfully developed to study several of these.

A first issue is how our results would differ if we focus on subgame perfect equilibria rather than Markovian equilibria (e.g., as in MPCE or MPME). While the Markovian restriction in the MPCE is not central, we cannot give a comprehensive answer to this question for the monopolistic environment because characterizing the entire set of subgame perfect equilibria turns out to be a very challenging problem. It can be shown that subgame perfect equilibria must satisfy two incentive compatibility constraints, one ensuring that country $A$ does not declare war (which essentially requires country $A$ 's continuation utility to be greater than (22) evaluated at $m^{*}\left(e_{t}\right)$ given by (8)) and one ensuring that country $S$ does not deviate from the equilibrium path of offers given the current level of armament by country $A$ (and anticipating that any sufficiently attractive offer to country $A$ can deter it from war). This description implies that, similar to the MPME, country $A$ will have an incentive to arm in subgame perfect equilibria. For example, suppose that preferences satisfy $\frac{-u^{\prime}(x)}{\left(x u^{\prime \prime}(x)\right)}<1$ for all $x$. Since $w(0)=0$, it can be shown in this situation that $V\left(w(0) e_{t}\right)=-\infty$ for all $e_{t}$. Suppose that country $A$ chose 0 armament at date $t$, then country $S$ could extract an arbitrarily large payment from country $A$ while still avoiding war because rejection of the offer would provide infinite disutility to country $A$. However, this would not be incentive compatible for country $A$ at the armament stage since it could instead deviate to armament level $m^{*}\left(e_{t}\right)$, go to war, and make itself strictly better off. This implies that subgame perfect equilibria have much in common with MPME and suffer from the same commitment problem on the part of country $S$ - that is, country $S$ will be unable to commit to offering attractive terms of trade to country $A$ if the latter does not invest in armaments. 
However, a full characterization of the path of distortions requires us to first determine the "worst subgame perfect equilibrium" from the viewpoint of both countries, which turns out to be very difficult. For this reason, we have focused on Markovian equilibria, even though the argument here suggests that certain economic insights continue to hold with subgame perfect equilibria.

A second issue is whether alternative arrangements could emerge as a way of preventing war and the costs of armaments. One possibility would be a leasing agreement, where country $S$ may sell or lease its resource fields to country $A$, thus reducing or eliminating future armaments. We believe that this is an interesting possibility, though it raises its own set of commitment issues. In particular, in the same way that country $S$ can renege on any promise concerning future prices, it can renege on its lease contract and "nationalize" the resource fields. Then country $A$ would need to arm to ensure that its lease contract is not violated. If we again focus on Markovian equilibria, violation of lease contracts may be attractive to country $S$ and may preclude leasing along the equilibrium path. On the other hand, it may well be the case that country $A$ could protect the lease contract with lower investment in armaments than the one necessary for war. This discussion highlights that the exact implications of leasing would depend on how leasing differs from spot market transactions, particularly in regard to the type of military might that needs to be exercised to support such transactions.

A related but distinct issue is that country $S$ may voluntarily choose to be "colonized" by country $A$ instead of going to war. Such colonization might be attractive relative to the payoff from war, $\psi$. Such an arrangement, however, raises new issues. Country $A$ may again be forced to invest in armaments to protect these resources, for example, against an insurrection from its colonial subjects. Once again, exactly what types of military investments need to be made to support different types of contractual arrangements becomes central.

Yet another issue that can be studied using an extended version of this framework concerns the nature of equilibrium when country $A$ can switch to a different technology. For example, when the resource in question is oil, country $A$ could have access to a backstop technology in the form of nuclear power, coal, or perhaps green technologies. This possibility can be analyzed 
using our framework, though the main results need to be modified because the Inada conditions no longer hold and the possibility of a switch to another technology affects incentives at all points in time.

Finally, our framework ignores domestic political economy issues, which are obviously critical in the context of exploitation of and conflict over natural resources. For example, most of the gains from natural resource income may accrue to an elite in country $S$, as they do, for example, in Saudi Arabia, Kuwait, United Arab Emirates, or even Iran, whereas the cost of war may be borne by all citizens. Similarly, in country $A$ there may be different constituencies in favor of different types of trade and military relationships with country $S$. The analysis of the interactions between domestic politics and dynamic trade of natural resources is another interesting area that can be studied by a (significant) generalization of our framework.

\section{CONCLUSION}

This article analyzed a dynamic environment in which a resource-rich country trades an exhaustible resource with a resource-poor country. In every period, the resource-poor country can arm and attack the resource-rich country. When the resource is extracted by price-taking firms, there is a novel externality as each firm fails to internalize the impact of its extraction on military action by the resource-poor country. In the empirically relevant case where the demand for the resource is inelastic and the resource-poor country can capture most of the remaining endowment in a war, war becomes inevitable. Because the anticipation of future war encourages more rapid extraction, in the case of nonbinding extraction limits, equilibrium war happens in the initial period.

Externalities across price-taking firms can be internalized by the government of the resource-rich country regulating the price and the level of production of the resource. This "monopolistic" environment can prevent wars even when they occur under competitive markets. The resource-rich country does so by making offers that leave the resource-poor country indifferent between war and peace at each date. Interestingly, this involves a deviation from the Hotelling rule because, depending on whether incentives for war are increasing or decreasing in the remaining endowment of the resource, the resource-rich country prefers to 
adopt a slower or more rapid rate of extraction of the resource than that implied by the Hotelling rule. In particular, in the empirically relevant case where the demand elasticity for the resource is less than 1 , extraction is slower and resource prices increase more slowly than under the Hotelling rule because this enables the resource-rich country to slow down the rise in armaments, for which it is paying indirectly. Conversely, when demand is elastic, the resource-rich country can reduce armament costs by adopting a more rapid path of resource extraction than the one implied by the Hotelling rule.

Nevertheless, a naive conjecture that regulation of prices and quantities by the resource-rich country will necessarily prevent war and make its citizens necessarily better off is also incorrect. The monopolistic environment, which allows for such regulation and in fact gives the resource-rich country the ability to make take-it-or-leave-it offers, leads to a different type of distortion: because the resource-rich country cannot commit to making attractive offers to the resource-poor country without the latter arming, the equilibrium path involves armaments at each date. The resource-rich country must then, implicitly, pay the future costs of armaments to prevent war. This might, paradoxically, make war more likely than the competitive equilibrium.

Finally, we also showed that the main insights generalize to the case where there are several countries competing for resources and where the resource-rich country can also invest in armaments for defense.

We view this article as a first step in the analysis of interactions between dynamic trade and intercountry military actions. These ideas appear particularly important in the context of natural resources because their trade is necessarily dynamic and international trade in natural resources has historically been heavily affected by military conflict or the threat thereof. Despite the simplicity of the economic environment studied here, both under competitive markets and when the resource-rich country can regulate prices and quantities, there are rich interactions between economic equilibria and international conflict. In particular, the path of prices is affected by the future probabilities of war, while simultaneously the likelihood of war is shaped by the paths of prices and quantities. We think that further study of dynamic interactions between trade, international conflict, and political economy, including the several areas mentioned in Section VI.C. , is a fruitful area for future research. 


\author{
MASSACHUSETTS INSTITUTE OF TECHNOLOGY \\ YALE UNIVERSITY \\ YALE UNIVERSITY \\ COLUMBIA UNIVERSITY
}

\title{
SUPPLEMENTARY MATERIAL
}

An Online Appendix for this article can be found at QJE online (qje.oxfordjournals.org).

\section{REFERENCES}

Acemoglu, Daron, and James A. Robinson, Economic Origins of Dictatorship and Democracy (New York: Cambridge University Press, 2006).

Anderlini, Luca, Dino Gerardi, and Roger Lagunoff, "Social Memory, Evidence, and Conflict," Review of Economic Dynamics, 13 (2010), 559574.

Antrás, Pol, and Gerard Padró i Miquel, "Foreign Influence and Welfare," Journal of International Economics, 84 (2011), 135-148.

Baramki, Dimitri, Phoenicia and the Phoenicians (Lebanon: Khayats, 1961).

Bagwell, Kyle, and Robert W. Staiger, "A Theory of Managed Trade," American Economic Review, 80 (1990), 779-795.

- "Domestic Policies, National Sovereignty and International Economic Institutions," Quarterly Journal of Economics, 116 (2001), 519-562.

Bakeless, John Edwin, The Economic Causes of Modern War: A Study of the Period: 1878-1918 (New York: Mofatt, Yard, 1921).

Baliga, Sandeep, and Tomas Sjöström, "Arms Races and Negotiations," Review of Economic Studies, 71 (2004), 351-369.

Bohn, Henning, and Robert T. Deacon, "Ownership Risk, Investment, and the Use of Natural Resources," American Economic Review, 90 (2000), 526-549.

Caselli, Francesco, "Power Struggles and the Natural Resource Curse," Working Paper, 2006.

Crow, John A., The Epic of Latin America (Berkeley: University of California Press, 1992).

Chassang, Sylvain, and Gerard Padró i Miquel, "Conflict and Deterrence under Strategic Risk," Quarterly Journal of Economics, 125 (2010), 1821-1858.

Dasgupta, Partha, and Geoffrey M. Heal, Economic Theory and Exhaustible Resources (Cambridge: Cambridge University Press, 1979).

Dennis, William J., "Documentary History of the Tacna-Arica Dispute," University of Iowa Studies in Social Sciences, 9 (1927), 3-261.

Dixit, Avinash, "Strategic Behavior in Contests," American Economic Review, 77 (1987) 891-898.

Egorov, Georgy, Sergei Guriev, and Konstantin Sonin, "Why Resource-Poor Dictators Allow Freer Media: A Theory and Evidence from Panel Data," American Political Science Review, 103 (2009), 645-668.

Engel, Eduardo, and Ronald Fischer, "Optimal Resource Extraction Contracts under Threat of Expropriation," in The Natural Resource Trap: Private Investment without Public Commitment, William Hogan and Frederico Sturzenneger, eds. (Cambridge, MA: MIT Press, 2010), 161-196.

Esteban, Joan, and Debraj Ray, "On the Salience of Ethnic Conflict," American Economic Review, 98 (2008), 2185-2202.

Farcau, Bruce W., The Ten Cents War: Chile, Peru, and Bolivia in the War of the Pacific, 1879-1884 (Westport, CT: Praeger, 2000).

Fearon, James D., "Rationalist Explanations for War," International Organization, 49 (1995), 379-414. 
Findlay, Ronald, and Kevin H. O'Rourke, Power and Plenty: Trade, War, and the World Economy in the Second Millennium (Princeton, NJ: Princeton University Press, 2007).

Garfinkel, Michelle R., and Stergios Skaperdas, "A Conflict without Misperceptions or Incomplete Information: How the Future Matters," Journal of Conflict Resolution, 44 (2000), 793-807.

Garfinkel, Michelle R., Stergios Skaperdas, and Constantinos Syropoulos, "International Trade and Transnational Insecurity: How Comparative Advantage and Power Are Jointly Determined," Working Paper, 2009.

_ , "Trade and Insecure Resources: Implications for Welfare and Comparative Advantage," Working Paper, 2011.

Gately, Dermot, and Hillard Huntington, "The Asymmetric Effects of Changes in Price and Income on Energy and Oil Demand," Energy Journal, 23 (2002), $19-37$.

Grossman, Gene, and Elhanan Helpman, "Trade Wars and Trade Talks," Journal of Political Economy, 103 (1995), 675-708.

Hirshleifer, Jack, "Anarchy and its Breakdown," Journal of Political Economy, 103 (1995), 26-52.

Homer-Dixon, Thomas, "On the Threshold: Environmental Changes as Causes of Acute Conflict," International Security, 16 (1991), 76-116.

- Environment, Scarcity, and Violence (Princeton, NJ: Princeton University Press, 1999).

Hotelling, Harold, "The Economics of Exhaustible Resources," Journal of Political Economy, 39 (1931), 137-175.

Jackson, Matthew O., and Massimo Morelli, "Strategic Militarization, Deterrence, and Wars," Quarterly Journal of Political Science, 4 (2009), 279-313.

Kasoff, Ben, "Cedars of Lebanon, Babylon and Conflict," ICE Case Study, 1997; http://www1.american.edu/TED/cedars.htm.

Klare, Michael T., Resource Wars: The New Landscape of Global Conflict (New York: Henry Holt, 2001).

Kremer, Michael, and Charles Morcom, "Elephants," American Economic Review, 90 (2000), 212-234.

Long, Ngo Van, "Resource Extraction under the Uncertainty about Possible Nationalization," Journal of Economic Theory, 10 (1975), 42-53.

Maggi, Giovanni, "The Role of Multinational Organizations in International Trade Cooperation," American Economic Review, 89 (1999), 190-214.

Maggi, Giovanni, and Andres Rodriguez-Clare, "A Political-Economy Theory of Trade Agreements," American Economic Review, 97 (2007), 1374-1406.

Matthew, William M., "Peru and the British Guano Market 1840-1870," Economic History Review, 23 (1970), 112-128.

McBride, Michael, Gary Milante, and Stergios Skaperdas, "War and Peace with Endogenous State Capacity," Journal of Conflict Resolution, 55 (2011), 446-468.

Meiggs, Russell, Trees and Timber in the Ancient Mediterranean (Oxford: Clarendon Press, 1982).

Mikesell, Marvin W., "The Deforestation of Mount Lebanon," Geographical Review, 59 (1969), 1-28.

Nemet-Nejat, Karen R., Daily Life in Ancient Mesopotamia (Westport, CT: Greenwood, 1989).

Pindyck, Robert S., "The Optimal Exploration and Production of Nonrenewable Resources," Journal of Political Economy, 86 (1978), 841-861.

Powell, Robert, "Guns, Butter, and Anarchy," American Political Science Review, 87 (1993), 115-132.

_ In the Shadow of Power: States and Strategies in International Politics (Princeton, NJ: Princeton University Press, 1999).

Richardson, Lewis F., Statistics of Deadly Quarrels, Quincy Wright and C. C. Lienau eds. (Chicago: Quadrangle Books, 1960).

Robinson, James A., and Ragnar Torvik, "Political Foundations of the Resource Curse," Journal of Development Economics, 79 (2006), 447-468.

Ross, Michael L., "The Political Economy of the Resource Curse," World Politics, 52 (1999), 297-322. 
Semple, Ellen Churchill, Geography of the Mediterranean Region (New York: Henry Holt, 1931).

Schwarz, Michael, and Konstantin Sonin, "A Theory of Brinksmanship, Conflicts, and Commitments," Journal of Law, Economics, and Organization, 24 (2008), 161-183.

Sicotte, Richard, Catalina Vizcarra, and Kirsten Wandschneider, "The Fiscal Impact of the War of the Pacific," Cliometrica, 3 (2009), 97-121.

Skaperdas, Stergios, "Cooperation, Conflict, and Power in the Absence of Property Rights," American Economic Review, 82 (1992), 720-739.

Tornell, Aaron, and Philip R. Lane, "The Voracity Effect," American Economic Review, 89 (1999), 22-46.

Toset, Hans P., Nils P. Gleditsch, and Havard Hegre, "Shared Rivers and Interstate Conflict," Political Geography, 19, no. 8 (2000), 971-996.

Vizcarra, Catalina, "Guano, Credible Commitments, and Sovereign Debt Repayment in Nineteenth-Century Peru," Journal of Economic History, 69 (2009), 358-387.

Westing, Arthur H., Global Resources and International Conflict: Environmental Factors in Strategic Policy and Action (Oxford: Oxford University Press, 1986).

Wright, Quincy, A Study of War (Chicago: University of Chicago Press, 1942).

Yared, Pierre, "A Dynamic Theory of War and Peace," Journal of Economic Theory, 145 (2010), 1921-1950. 